\title{
Spectral characterization and quality assessment of organic compost for agricultural purposes
}

\author{
Anchal Sharma ${ }^{1} \cdot$ Rajiv Ganguly ${ }^{1}\left[\right.$ ] Ashok Kumar Gupta ${ }^{1}$
}

Received: 26 June 2018 / Accepted: 13 November 2018 / Published online: 20 November 2018

(c) The Author(s) 2018

\begin{abstract}
Purpose The study presents the physico-chemical, heavy metal and spectral characterization of aerobic compost to assess the suitability of its use for different purposes generated from two different municipal solid waste dumpsites located in the cities of Solan and Mandi in Himachal Pradesh.

Methods The spectral characteristics of the compost material were determined using Scanning Electron Microscope (SEM), Energy Dispersive Spectroscopy (EDS) and X-ray Diffraction (XRD) technique. The heavy metal analysis of compost material was analyzed through atomic absorption spectroscopy (AAS). The study also focused on the determination of the qualitative nature of compost by utilizing an indexing method based on Fertilizer Control Order (FCO) Standards. The utility of the compost was characterized on the values of 'Fertility Index' and 'Clean Index'.

Results The Fertility Index (FI) of compost for Solan and Mandi was observed 3.5 and 3.6, respectively, whereas Clean Index (CI) of compost for both regions was observed 4.0 and 5.0 at the 60th day of sampling, respectively, with the former being classified as category D and the second being classified as category A of high fertilizing potential.

Conclusions The MSW compost of Solan cannot be used as fertilizer due to its low fertilizing potential. The heavy metal concentration for the study regions has been found within the permissible limits of the fertility control order standards. It is concluded from the study that aerobic composting is a suitable option for processing of waste as well as it can reduce the weight of organic waste in the dumpsite.
\end{abstract}

Keywords Compost $\cdot$ Heavy metal $\cdot$ Scanning electron microscopy $\cdot$ X-ray diffraction $\cdot$ Fertility index $\cdot$ Clean index

\section{Introduction}

The existing scenario of municipal solid waste management in Indian cities is highly unsatisfactory (Rawat et al.2013; Sharma et al. 2017). It is reported that the total municipal solid waste generated in India is 1,35,198 tons per day (TPD) (CPCB 2010). Of the total waste generated in India, the overall collection efficiency of waste is only $70 \%$ and treated waste accounts for $12.5 \%$ and the remaining proportion (17.5\%) not being collected. The average collection

Electronic supplementary material The online version of this article (https://doi.org/10.1007/s40093-018-0233-7) contains supplementary material, which is available to authorized users.

Rajiv Ganguly

rajiv.ganguly@juit.ac.in; rajiv.phd@gmail.com

1 Department of Civil Engineering, Jaypee University of Information Technology, District Solan, Waknaghat, Himachal Pradesh 173234, India efficiency municipal solid waste in Indian cities is significantly influenced by lack of adequate waste transportation vehicles with a reported study mentioning that almost $70 \%$ of cities in India in lacking such basic facilities (Sharma et al.2018). Further, the enhanced rate of migration from rural to the urban areas has led to overwhelming demographic growth in many cities worldwide including India. In today's burgeoning economy, with rapid industrialization majority of Indian population has rapidly migrated from rural to urban areas. This has led to further increased growth of municipal solid waste (MSW) generated in urban areas. The variation in the waste fraction mainly depends on the economic condition of the city (Sarkar and Chourasia 2017). Presently, the rate of MSW generation in India varies from 0.2 to $0.87 \mathrm{~kg}$ per capita per day (Kumar and Goel 2009; Rana et al. 2018) varying from rural to urban locations and this is expected to increase further for urban areas. The management of municipal solid waste generated in most of the Indian cities is a problematic issue with slightly better 
management practices in Metro and Tier-I cities due to slightly increased resources. However, with increased generation rates of MSW along with growth and influx of population in these cities, a critical stage is being reached due to the unavailability of adequate facilities to treat and dispose such voluminous quantities of wastes (Gupta and Arora 2016). This poor management of municipal solid waste in developing countries including India is of severe concern, particularly with open dumping of wastes being the easiest and cost-effective methods of disposal (Kumar et al. 2009; Shekdar 2009). The lack of waste management including collection and treatment of waste leads to global warming because organic waste fraction is one of the causes of gas emission (Pandyaswargo et al. 2014).

Recycling, incineration, composting, open burning, and dumping in open landfills are some of the other components of solid waste management processes. However, the waste disposal in the scientific way is the matter of concern in today's growing world (Sudharmaidevi et al. 2017). Further, with rapid increase in the population rates which influence the characterization and generation patterns of municipal solid waste (Srivastava et al. 2014) coupled with enhanced urbanization and industrialization in the developing countries are the major reasons for developing an appropriate municipal solid waste management systems (Rawat et al. 2013).

The characterization of municipal solid waste is an important feature in determining suitable waste management practices in the studies. In principle, the reported literature for characterization of waste in Indian cities reveal a high proportion of biodegradable organics followed by paper and inert (Rana et al. 2018; Hancs et al. 2011; Gomez et al. 2008). For example, it has been reported that the maximum percentage by weight of components in Indian metro cities is organic waste $(41 \%)$, paper $(6 \%)$, plastic $(4 \%)$, glass (2\%), metal (2\%), textile (4\%), leather (1\%) and inert (40\%) (Sharholy et al. 2008) which has also been corroborated in separate other studies reporting that MSW generated in Indian context consists of $45-60 \%$ organic matter, 6-10\% recyclables, and the rest as inert matter (Kumar et al. 2009). Municipal solid wastes produced from municipal services including street sweeping, dead animals waste, vegetable market wastes, domestic wastes, commercial wastes and institutional wastes. Moreover, the municipal solid waste consists of huge quantity of health hazardous and toxic chemicals and due to the direct exposure of solid waste to water and soil leads to environmental pollution (Puri et al. 2008; Sethi et al. 2013).

The state of Himachal Pradesh is predominantly a hilly region and has been reported to be the least urbanized consisting of only 59 urban agglomerations (Bharti et al. 2014). The overall rate of waste generation in Himachal Pradesh is about 350 TPD ( $0.413 \mathrm{~kg}$ per capita per day) which is
Table 1 Estimated waste generation in Himachal Pradesh (TERI2015)

\begin{tabular}{lllll}
\hline Sr. no. & Year & $\begin{array}{l}\text { Per capita waste } \\
\text { generation }\end{array}$ & $\begin{array}{l}\text { Urban popula- } \\
\text { tion }(* 1000)\end{array}$ & $\begin{array}{l}\text { Waste gener- } \\
\text { ated (tons/ } \\
\text { day) }\end{array}$ \\
\hline 1. & 2011 & 0.413 & 736.33 & 304.3 \\
2. & 2021 & 0.472 & 883.32 & 416.6 \\
3. & 2031 & 0.538 & 1023.42 & 550.9 \\
4. & 2041 & 0.614 & 1155.249 & 709.6 \\
\hline
\end{tabular}

Table 2 Physical characterization of municipal solid waste in study regions

\begin{tabular}{llcc}
\hline Sr. no. & Parameters & Solan & Mandi \\
\hline 1. & Density $\left(\mathrm{Kg} / \mathrm{m}^{3}\right)$ & $530.00 \pm 19.70$ & $516.67 \pm 25.17$ \\
2. & Organic waste & $55.36 \pm 2.16$ & $54.20 \pm 2.03$ \\
3. & Paper & $16.06 \pm 3.44$ & $17.33 \pm 0.68$ \\
4. & Plastic & $5.04 \pm 1.13$ & $7.04 \pm 0.62$ \\
5. & Glass & $4.20 \pm 2.13$ & $3.16 \pm 0.02$ \\
6. & Metal & $2.89 \pm 1.10$ & $2.55 \pm 0.36$ \\
7. & Inert & $6.89 \pm 1.17$ & $6.52 \pm 0.46$ \\
8. & Rubber & $3.23 \pm 0.57$ & $2.52 \pm 0.56$ \\
9. & Textile & $6.33 \pm 1.17$ & $6.72 \pm 1.60$ \\
\hline
\end{tabular}

much less than the national average generation rates of 100,000-135,000 TPD (Bharti et al. 2014). However, the population and thereby the per capita waste generation rate is expected to increase over the coming decades and the predicted rates are shown in Table 1.

The MSW generated in Himachal Pradesh has certain traits that are particularly different from other geographical regions including localized dumpsites, lesser population density, and large climatic variations, making it difficult to follow proper waste management practices (Sharma et al. 2018). Further, the issue of municipal solid waste management is becoming more sensitive due to influence of other factors including rapid population growth, increased developmental activities (for urbanization and modernization) and improved socio-economic conditions and improved standard of living in Himachal Pradesh (Bharti et al. 2014). With the advent of increased industrialization and thereby higher income levels has led to greater use of resources leading to the increased MSW generation and more complex composition of MSW than earlier (HP solid waste management strategy report 2015). In principle, the increased rate of generation of waste is an index of socio-economic development and economic prosperity of the region. In this context, the biodegradable fraction generated in Himachal Pradesh is significantly on the higher side (greater than $50 \%$ ) in comparison to plain areas in the country. The average physical characterization of municipal solid waste considering 
seasonal variations in the study regions of Himachal Pradesh is shown in Table 2.

The results revealed that more than half of the fraction of solid waste comprised of biodegradable waste, with paper waste the second highest fraction out of the total municipal solid waste in Himachal Pradesh. The chemical characterization of the municipal solid waste revealed that the sufficient amount of moisture content and organic matter present in the solid waste (Sharma et al. 2018) that is suitable for the composting process (NEERI report 2009). The observations from the physical characterization of the municipal solid in the study regions including Solan and Mandi (Himachal Pradesh) revealed that municipal solid waste is rich in organic waste, and hence composting is the one of the most viable options for the processing of municipal solid waste, thereby reducing the burden of waste on the landfill.

Composting is a biological decomposition process that converts organic matter into stabilized nutrient-rich products by microbial activities that can be used for the enrichment and nourishment of soil fertility (Manohara et al. 2017; Malakahmad et al. 2017). Aerobic composting process utilizes oxygen in a controlled condition to biologically decompose the solid wastes, whereas anaerobic composting is processed in the absence of oxygen (Manohara et al. 2017). Further, aerobic composting takes shorter time for the degradation than anaerobic composting, and emission of unpleasant odor can also be reduced (Rawat et al. 2013). The most promising strategies to improve the municipal solid waste management system include minimization of the amount of solid wastes generated, maximization of waste recycling as well as resource recovery (Mbuligwe et al. 2002). The application of compost to the agricultural land is a low-cost alternative to open landfill disposal or incineration (Bruun et al. 2006). Compost is a good soil fertilizer as it contains major nutrients to plants including nitrogen, phosphorus and potassium and organic material that boost soil properties by increasing aeration of soil and water holding capacity (Ingelmo et al. 2012).

It is important to note that the compost from municipal solid waste also has the possibility of bioaccumulation of heavy metals and may cause threat to human health when transferred to the food chain. The presence of heavy metals may cause blood-related problems and bone disorders, kidney and neurological damage (Bruun et al. 2006). Therefore, the application of the compost needs to be regulated depending upon the concentration of the heavy metal present in the compost samples. Different compost preparing companies use different composting techniques and non-uniform feedstock leading to production of different grades of compost (Saha et al. 2010). Further, the nature of the compost is highly influenced by the type, available composting facility, methodology used and the maturation period (Hargreaves et al. 2007). The nature of compost generated from mixed waste (without segregation) is often of poor quality and nonmarketable leading to financial losses. In this context, certain specific standards have been set to grade the compost generated and its specific use pertaining to that grade. In Indian conditions, such standards have been prescribed by Fertilizer Control Order (FCO) Standards, Government of India, 1985. However, the Quality Control (QC) Protocol of the FCO standards suffered from several drawbacks including the quality of composts being compliant with requisite fertilizing parameter but non-compliant in context of heavy metal being allowed for potential reuse, thereby causing harm and limiting the safe utilization of the organic waste generated. Further, the original FCO standards failed in identifying the overall quality compost due to input and type of composting method used, thereby rejecting better quality MSW composts generated using better techniques (Saha et al. 2010). In this context, a revised method for classification of compost was proposed to maximize the potential of compost generated, prevent contamination of agricultural soil and provide best resource utility to compost manufacturers and this was based on the computational values of clean index and fertility index. This enables the end users in identifying the application of the compost ranging from its application in growth of high value crops, food crops, gardening, etc. (Saha et al. 2010).

The present study focused on the determination of physico-chemical and spectroscopic characterization of compost generated from the dumpsites of two regions including Solan and Mandi region in Himachal Pradesh to analyze the nutrient concentration and structural changes during the composting process and is further assessed for its potential use in compliance with the revised methodology by the determination of its 'Fertility Index' and 'Clean Index'

\section{Study area}

Mandi town lies in the coordinates of $31.5892^{\circ} \mathrm{N}$ and $76.9182^{\circ} \mathrm{E}$ and having the population of 26,422 . The municipal solid waste generation rate is 21 tons per day out of which 12.5 TPD is directly disposed of in open land. The collection efficiency is reported as $60 \%$ in the study region which is unsatisfactory for efficient waste management system (Sharma et al. 2018).

Solan town lies within the coordinates of $30.9045^{\circ} \mathrm{N}$ and $77.0967^{\circ} \mathrm{E}$ with the population of 39,256 . The total waste generation rate is estimated in the range of 21-22 tons per day out of which 13-15 tons per day is openly disposed off in an unsatisfactory manner, whereas the collection efficiency of the town has been reported as $60 \%$ only (Sharma et al. 2018). Further, a small fraction of the waste load (about 5TPD) is being presently transferred to another alternative treatment plant which basically treats waste generated from 


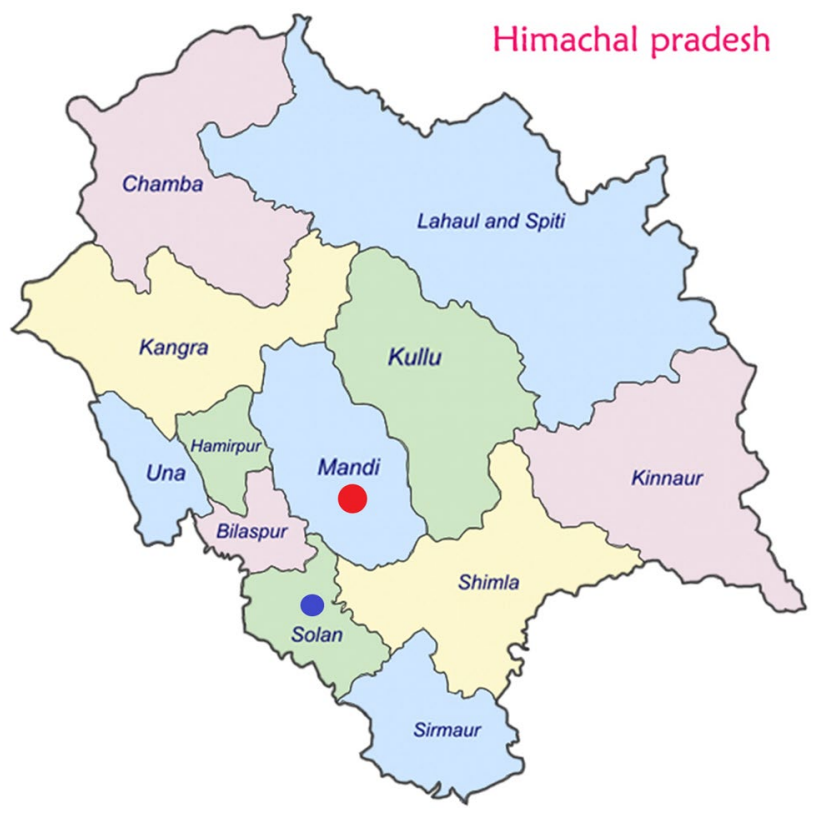

Fig. 1 Location map of study areas (Himachal Pradesh, India)

Shimla district of Himachal Pradesh. Figure 1 denotes the locations of the collected study area.

\section{Composting mechanism at the study location}

The mechanism of compost generation in the study regions of Solan and Mandi of Himachal Pradesh generally follows the aerobic windrow composting technique involving the pilling of organic waste in long rows. The height and width of the pile are generally kept between 4-6 feet and 14-16 feet, respectively (Mazumdar 2007). However, the piles at both the study locations were of smaller dimensions than the standard conditions primarily due to less quantity of waste being generated. However, the turning of windrow after 20 days of stabilization process is generally carried out manually to improve aeration, proper mixing and removal of moisture at both study locations. Thereafter, screening of the stabilized material is carried out after 5-6 weeks with a further curing for almost 2 weeks. At the end of the composting process, segregation of the cured compost is performed by extracting out of small pieces of paper, plastic and other remaining materials observed in the prepared compost. The major drawback as observed in the existing system of composting was that the practice was carried out on mixed waste with segregation of material taking place after the compost has been generated, wherein in actuality the process should be in reverse chronology.

\section{Materials and methods}

\section{Sampling procedure and analysis}

The compost samples were collected in three stages of decomposition, i.e., on 20th day, 40th day and 60th day of composting process as per the procedure outlined in USEPA Part 503 Rule (USEPA 1995). Temperature $\left({ }^{\circ} \mathrm{C}\right)$ of the compost samples was observed during the collection of samples from the composting piles of both the study regions.

The moisture content of the compost samples was determined by the gravimetric method, wherein the samples were oven dried at $70{ }^{\circ} \mathrm{C}$ and loss of weight measured (Saha et al. 2010; Mandal et al. 2014). Bulk density was determined using a $100 \mathrm{ml}$ measuring cylinder, by tapping 30 times from a height of $40 \mathrm{~mm}$ (Saha et al. 2010; Mandal et al. 2014). $\mathrm{pH}$ and electrical conductivity were measured from dried slurry sample prepared in 1:5 compost-water suspension as per the procedure laid out in FAI (FAI 2007)and IS codes (IS 2720, Part 26, 1986). The concentrations of total organic carbon (TOC), total nitrogen (TN) and total phosphorous (TP) were determined as per the procedure mentioned in IS-10158 (1982). Sodium and potassium were estimated by flame photometry method (Manohara and Belagali 2016). Calcium and magnesium were estimated by titration method, i.e., using an ammonium acetate (1:5) extract with standard EDTA solution using Eriochrome Black-T indicator and Patton-Reeder's indicators (Manohara and Belagali 2016). The heavy metal parameters including lead, zinc, cadmium, chromium, copper, and nickel were evaluated through atomic absorption spectroscopy. In this context, the fine fraction of the compost samples was prepared by digesting $3 \mathrm{~g}$ of sample with $25 \mathrm{ml}$ of triacid (nitric acid:sulfuric acid:perchloric acid in a 9:2:1 ratio) at $120^{\circ} \mathrm{C}$ using a digester with microprocessor controller as per the procedure given in D5198-09 (ASTM D 2003).

\section{Instrumentation analysis}

For material analysis, highly sophisticated instruments were used for detection of structural changes of the compost and as such some of the finer aspects of the instrumentation analysis, have been discussed here.

\section{SEM-EDS analysis of compost samples}

Scanning electron microscopy (SEM) provides high resolution image of the solid material by focus an electron beam across the surface. Energy Dispersive X-Ray Spectroscopy (EDS) is an apparent technique that is used for the elemental identification of the material and also procure information regarding quantitative composition 
(Adefemi and Awokunmi 2009; Kiran and Srikantaswamy 2014). In the present study, structural changes of the compost samples during various stages of municipal solid waste degradation from two different regions were analyzed through Scanning Electron Microscopy and element detection through EDS (SEM-EDS) technique. The municipal solid waste compost sample (200 mg) was oven dried and heated at $550^{\circ} \mathrm{C}$ for $35 \mathrm{~min}$ and crushed in very fine particles, and then a small portion of the representative compost sample was sprinkled onto double sided carbon tape and readings were taken from FEG Quanta instrument and thus obtained the morphology of the compost material. The samples were evaluated at a wavelength of $0.01 \mathrm{Nm}$ for $15 \mathrm{~min}$ (Sharma et al. 2018).

\section{XRD analysis of compost samples}

$\mathrm{X}$-ray diffraction is the important tool that is used for the evaluation of the atomic and molecular structure of a crystal or any other inorganic material, which causes $\mathrm{X}$-ray beam to diffract into specific directions and each signal in the X-ray diffraction, represents the plane of crystal (Manohara et al. 2017). The overall structural changes during the decomposition process of the crystalline compounds can be evaluated using X-Ray Diffraction method. Thereafter by measuring the angles and intensities of diffracted beams, a crystallographer can produce a three-dimensional diagram of the density of electrons within the crystal (Kiran and Srikantaswamy 2014). The electron density is used to determine the mean positions of the atoms and their chemical bonds in the crystal. The compost samples were prepared by compressing them into fine powder, and the spectra of different samples were obtained on XRD instrument (Philips X-ray diffractometer). The sample size used was $200 \mathrm{mg}$ and was subjected to wavelength of $1.54 \mathrm{Nm}$ for the duration of 20 min each per sample. The scan axis used was gonio with the goniometer radius as $240 \mathrm{~mm}$. The angle used was $2 \theta$ and anode material used was copper. The fixed divergence slit type was used; $\mathrm{K}$ alpha was maintained at 1.54060 and spinning was employed. The temperature was maintained at $25^{\circ} \mathrm{CC}$ with the specimen length of 10 mm (System instruction manual PW 1349 \& Operation manual PE 1612).

\section{Atomic absorption spectroscopy (AAS) of compost samples}

Heavy metal analysis was accomplished on an atomic absorption spectroscopy (AAS, GBC Avanta) with D2 background correction lamp, and acetylene flame was used as fuel for higher concentrations while electro thermal atomization in graphite furnace with argon as carrier gas was employed for lower concentrations (Manohara and Belagali 2016).

\section{Indices for compost quality}

The quality of the compost samples at both the study locations is characterized by the terms 'Fertility Index' (FI) and 'Clean Index' (CI) based on the revised indices method (Saha et al. 2010) to determine the usability of compost generated for their market value. The criteria for determination of 'weighing factor' to determine these parameters have already been discussed in the literature (Saha et al. 2010; Mandal et al. 2014). To summarize, the weighing factor for different parameters is varied based on a five-point scale (1-5) determined on the basis of its importance to improve soil productivity (Saha et al. 2010). The fertility index (FI) values of the compost samples are calculated using the following formula as shown in the following equation (Saha et al. 2010; Mandal et al. 2014):

$\mathrm{FI}=\frac{\sum_{n}^{i=1} S_{i} w_{i}}{\sum_{n}^{i=1} w_{i}}$,

where $S_{i}$ is the score value and $w_{i}$ is the weighing factor of the $i$ th fertility parameter of analytical data.

The weighing factor also varied from 1 to 5 based on the toxicity level of different parameters. The clean index (CI) values of compost are calculated using the following formula given by Saha et al. 2010. The higher value of CI indicated lesser heavy metal contamination and vice versa (Mandal et al. 2014),

$\mathrm{CI}=\frac{\sum_{n}^{j=1} S_{j} w_{j}}{\sum_{n}^{j=1} w_{j}}$,

where $S_{j}$ is the score value and $w_{j}$ is the weighing factor of the $j$ th heavy metal parameter of analytical data.

\section{Results and discussion}

\section{Physico-chemical characterization of compost}

The evaluation of quality of compost and its maturity and nutrient level is mandatory to determine the possible use of the compost generated (Mandal et al. 2014). The major parameters used for the evaluation of compost quality are summarized in Tables 3, 4 for both Solan and Mandi study regions, respectively.

The temperature of the compost samples on the 60th day of decomposition process was recorded to be 54 and 
$59^{\circ} \mathrm{C}$ for Solan and Mandi region, respectively. Same compost samples showed recorded temperatures of 60 and $64^{\circ} \mathrm{C}$ at Solan and Mandi when composting was carried out on 20th day. The changes in the temperature could be attributed to the exothermic process exhibited by the microbial decomposition of organic matter (Mandal et al. 2014).

This also signifies that during the decomposition process, temperatures are slightly elevated in comparison to the temperatures observed after complete degradation (Saha et al. 2010). The total organic carbon (TOC) signifies the amount of organic matter present in the municipal solid waste compost material. In this context, it was observed that the range of TOC for both the study regions was between 12 and $18 \%$ which is within the specified limits as reported in the literature, wherein it has been mentioned that TOC varied between 4 and $20 \%$ in most of the Indian cities (Saha et al. 2010).

Moisture content of the municipal solid waste compost is an important parameter as it helps determining the storage and the ease of transporting of the final compost material (Saha et al. 2010). As such, the range of moisture content of MSW compost for both the study regions varied in between
31 and $45 \%$, whereas the reported literature revealed the range between 3.6 and $45.4 \%$ for most of the Indian cities (Mandal et al.2014). However, the reported values were significantly higher than the standards prescribed by Fertility Control Order 1985, wherein the recommended value lies between 15 and 25\% (Saha et al. 2010). The $\mathrm{pH}$ of the compost samples for the study regions varied in the range from 7.84 to 7.08 from 20th day to 60th day of degradation process for Solan, whereas the same was observed in the range 8.24-7.48 from 20th day to 60th day of degradation process for Mandi. Hence, the $\mathrm{pH}$ values of the compost samples for both the study regions were within the alkaline-neutral range, thereby showing the decomposition of organic matter. The past studies revealed that the $\mathrm{pH}$ of municipal solid waste compost varied in the range from neutral to alkaline in one of the compost plants of Delhi which was not the sign of matured and nourished compost as a fertilizer. The alkalinity of $\mathrm{pH}$ leads to the formation of ammonium gas in the air that tends to increase the harmful pathogenic bacteria in the atmosphere (Mandal et al. 2014).

The electrical conductivity is another important parameter to determine the chemical properties and nutrition level of the compost (Manohar et al. 2016). The value of electrical
Table 3 Physico-chemical characterization of compost in Solan (H.P.)
Table 4 Physico-chemical characterization of compost in Mandi (H.P.)

\begin{tabular}{|c|c|c|c|c|c|}
\hline Sr. no. & Parameters & 20th day & 40th day & 60th day & FCO standards \\
\hline 1. & Temperature $\left({ }^{\circ} \mathrm{C}\right)$ & $60 \pm 2.33$ & $55 \pm 0.67$ & $54 \pm 1.23$ & - \\
\hline 2. & $\mathrm{pH}$ & $7.84 \pm 2.34$ & $7.33 . \pm 0.67$ & $7.08 \pm 0.92$ & $6.5-7.5$ \\
\hline 3. & Electrical conductivity $(\mathrm{dS} / \mathrm{m})$ & $6.7 \pm 0.44$ & $6.1 \pm 1.98$ & $5.8 \pm 0.22$ & $<4$ \\
\hline 4. & Moisture content (\%) & $45.00 \pm 0.66$ & $39.78 \pm 2.87$ & $33.02 \pm 0.42$ & $15-25$ \\
\hline 5. & Calcium (mg/l) & $12.08 \pm 0.33$ & $15.02 \pm 3.12$ & $16.24 \pm 0.98$ & - \\
\hline 6. & Magnesium (mg/l) & $9.72 \pm 1.66$ & $6.84 \pm 0.88$ & $5.59 \pm 0.22$ & - \\
\hline 7. & Organic carbon $(\%)$ & $18.28 \pm 2.37$ & $16.14 \pm 3.13$ & $14.22 \pm 0.65$ & $16(\min )$ \\
\hline 8. & Nitrogen $(\mathrm{mg} / \mathrm{Kg})$ & $0.64 \pm 0.28$ & $0.72 \pm 0.12$ & $0.80 \pm 0.33$ & $0.5(\min )$ \\
\hline 9. & Phosphorus (mg/Kg) & $2.34 \pm 1.45$ & $1.98 \pm 0.33$ & $0.92 \pm 0.28$ & $0.5(\min )$ \\
\hline 10. & Potassium $(\mathrm{mg} / \mathrm{Kg})$ & $14.1 \pm 0.24$ & $9.2 \pm 1.44$ & $7.40 \pm 0.98$ & 1 (min) \\
\hline 11. & $\mathrm{C} / \mathrm{N}$ ratio $(\%)$ & $29.28 \pm 1.92$ & $28.91 \pm 0.48$ & $26.02 \pm 3.12$ & $20(\min )$ \\
\hline
\end{tabular}

\begin{tabular}{|c|c|c|c|c|c|}
\hline Sr. no. & Parameters & 20th day & 40th day & 60th day & FCO standards \\
\hline 1. & Temperature $\left({ }^{\circ} \mathrm{C}\right)$ & $64 \pm 0.26$ & $62 \pm 1.18$ & $59 \pm 0.89$ & - \\
\hline 2. & $\mathrm{pH}$ & $8.24 \pm 0.24$ & $7.54 \pm 1.05$ & $7.48 \pm 2.84$ & $6.5-7.5$ \\
\hline 3. & Electrical conductivity $(\mathrm{dS} / \mathrm{m})$ & $6.00 \pm 0.33$ & $5.65 \pm 2.32$ & $5.23 \pm 0.67$ & $<4$ \\
\hline 4. & Moisture content (\%) & $42.92 \pm 0.33$ & $35.17 \pm 2.12$ & $31.00 \pm 3.04$ & $15-25$ \\
\hline 5. & Calcium (mg/l) & $15.24 \pm 1.67$ & $17.01 \pm 2.33$ & $17.89 \pm 0.42$ & - \\
\hline 6. & Magnesium (mg/l) & $10.02 \pm 0.66$ & $8.18 \pm 0.36$ & $7.24 \pm 1.59$ & - \\
\hline 7. & Organic carbon $(\%)$ & $17.40 \pm 0.48$ & $14.35 \pm 1.73$ & $12.46 \pm 0.21$ & $16(\min )$ \\
\hline 8. & Nitrogen (mg/Kg) & $0.69 \pm 0.28$ & $0.88 \pm 0.55$ & $0.92 \pm 1.23$ & $0.5(\min )$ \\
\hline 9. & Phosphorus (mg/Kg) & $2.86 \pm 1.03$ & $2.12 \pm 0.11$ & $0.78 \pm 0.63$ & $0.5(\min )$ \\
\hline 10. & Potassium (mg/Kg) & $16.20 \pm 2.67$ & $12.50 \pm 0.98$ & $9.20 \pm 1.33$ & $1(\min )$ \\
\hline 11. & $\mathrm{C} / \mathrm{N}$ ratio $(\%)$ & $30.01 \pm 0.88$ & $29.12 \pm 1.86$ & $28.32 \pm 0.31$ & $20(\min )$ \\
\hline
\end{tabular}


conductivity was observed to be $6.7 \mathrm{dS} / \mathrm{m}$ in the 20th day of composting period, $6.1 \mathrm{dS} / \mathrm{m}$ in 40th day of degradation and $5.8 \mathrm{dS} / \mathrm{m}$ in the 60th day of composting period for Solan region and was found to be comparatively less from Mandi region which reported $6.0 \mathrm{dS} / \mathrm{m}$ in 20th day of degradation, $5.65 \mathrm{dS} / \mathrm{m}$ in 40th day of degradation and $5.23 \mathrm{dS} / \mathrm{m}$ in the 60 th day of degradation period, respectively. The values at both the study locations slightly exceeded the permissible limits as prescribed by FCO India. Comparison with other reported literature for Indian cities reported similar values (Manohar et al. 2016; Mandal et al. 2014).

The concentration of macronutrients such as nitrogen, phosphorous and potassium (NPK) are important parameters to determine the quality of compost as fertilizer (Manohar et al. 2016). The concentration of nitrogen was found $0.64 \mathrm{mg} / \mathrm{kg}, 0.72 \mathrm{mg} / \mathrm{kg}$ and $0.80 \mathrm{mg} / \mathrm{kg}$ in the 20th day, 40th day and 60th day of composting period, respectively, for Solan region and $0.69 \mathrm{mg} / \mathrm{kg}, 0.88 \mathrm{mg} / \mathrm{kg}$ and $0.92 \mathrm{mg} /$ $\mathrm{kg}$ in the 20th day, 40th day and 60th day of composting period, respectively, for Mandi region and as per FCO standards, India (Saha et al. 2010). The phosphorus content of the compost samples was observed $2.34 \mathrm{mg} / \mathrm{kg}, 1.98 \mathrm{mg} /$ $\mathrm{kg}$ and $0.92 \mathrm{mg} / \mathrm{kg}$ in 20th day, 40th day and 60th day of composting period, respectively, for Solan region, whereas $2.86 \mathrm{mg} / \mathrm{kg}, 2.12 \mathrm{mg} / \mathrm{kg}$ and $0.78 \mathrm{mg} / \mathrm{kg}$ in 20th day, 40th day and 60th day of composting period, respectively, for Mandi region, respectively. Apart from this, the potassium content was observed $14.1 \mathrm{mg} / \mathrm{kg}, 9.2 \mathrm{mg} / \mathrm{kg}$ and $7.4 \mathrm{mg} / \mathrm{kg}$ in 20th day, 40th day and 60th day of composting period, respectively, for Solan region, whereas the concentration was observed slightly more for Mandi region as $16.20 \mathrm{mg} /$ $\mathrm{kg}, 12.50 \mathrm{mg} / \mathrm{kg}$ and $9.20 \mathrm{mg} / \mathrm{kg}$ in 20th day, 40th day and 60 th day of composting period. Reported concentrations for nitrogen, phosphorus and potassium were $0.702 \mathrm{mg} /$ $\mathrm{kg}, 2.1 \mathrm{mg} / \mathrm{kg}$ and $8.8 \mathrm{mg} / \mathrm{kg}$, respectively, at the end of the maturation stage for Mysore city compost pit (Manohar et al. 2016) and $0.5 \mathrm{mg} / \mathrm{kg}, 0.6 \mathrm{mg} / \mathrm{kg}$ and $5.8 \mathrm{mg} / \mathrm{kg}$ were reported for the compost plant of Delhi (Mazumdar 2007) and were quite similar to the values determined for the study locations including Mandi and Solan. It has been further reported in the literature that the compost prepared from rural municipal solid waste generally has a higher proportion of nitrogen and phosphorus content in comparison to
Table 6 Heavy metal analysis of compost in Mandi (H.P.)

\begin{tabular}{lllllr}
\hline Sr. no. & $\begin{array}{l}\text { Param- } \\
\text { eters }\end{array}$ & 20th day & 40th day & 60th day & $\begin{array}{l}\text { FCO } \\
\text { standards }\end{array}$ \\
\hline 1. & Lead & $8.48 \pm 1.66$ & $5.02 \pm 2.67$ & $2.18 \pm 0.81$ & 100 \\
2. & Zinc & $6.12 \pm 2.31$ & $5.27 \pm 1.22$ & $3.26 \pm 0.37$ & 1000 \\
3. & $\begin{array}{c}\text { Chro- } \\
\text { mium }\end{array}$ & $0.56 \pm 0.15$ & $0.44 \pm 1.32$ & $0.23 \pm 0.17$ & 50 \\
4. & Cad- & $0.25 \pm 0.33$ & $0.14 \pm 1.27$ & BDL & 5 \\
& mium & & & & \\
5. & Copper & $2.38 \pm 1.22$ & $1.57 \pm 1.25$ & $1.02 \pm 0.67$ & 500 \\
6. & Nickel & $9.87 \pm 2.98$ & $5.13 \pm 1.89$ & $3.26 \pm 0.33$ & 50 \\
\hline
\end{tabular}

prepared content from the urban waste (Saha et al. 2010). Similarly, it has been reported in the literature that compost generated from European countries has higher concentration of carbon, nitrogen and phosphorous (Saha et al. 2010).

The calcium and magnesium concentrations in compost are important for growth of microbes (Manohara et al. 2017). Further, these parameters determine the fertility potential of the compost at the maturation stage. The calcium content in the municipal solid waste compost was observed $12.08 \mathrm{mg} / \mathrm{l}$ in 20th day of composting, $15.02 \mathrm{mg} / \mathrm{l}$ in 40th day of composting and $16.24 \mathrm{mg} / \mathrm{l}$ in 60th day of composting period for Solan region, whereas it was observed $15.24 \mathrm{mg} / \mathrm{l}, 17.01 \mathrm{mg} / \mathrm{l}$ and $17.89 \mathrm{mg} / \mathrm{l}$ in 20th day, 40th day and 60th day of the composting process, respectively. Apart from this, the magnesium content was observed $9.72 \mathrm{mg} / \mathrm{l}, 6.84 \mathrm{mg} / \mathrm{l}$ and $5.59 \mathrm{mg} / \mathrm{l}$ in $20 \mathrm{th}$ day, 40th day and 60th day of the composting process, respectively, for Solan region, whereas it was observed slightly more for Mandi region, i.e., $10.02 \mathrm{mg} / \mathrm{l}$ in 20th day of composting, $8.18 \mathrm{mg} / \mathrm{l}$ in 40th day of composting process and $7.24 \mathrm{mg} / \mathrm{l}$ in 60th day of the composting process, respectively. The earlier studies reported the concentration of calcium and magnesium at the maturation stage in the range of $18.02 \mathrm{mg} / \mathrm{l}$ and $6.79 \mathrm{mg} / \mathrm{l}$ in compost pits of Mysore city as reported by Manohara et al. (2017). The total organic carbon content was observed 18.28, 16.24 and $14.22 \%$ in the 20th day, 40th day and 60th day of the composting process, respectively, for Solan region, whereas the same concentration was reported 17.40, 14.35 and $12.46 \%$ in the 20th day, 40th day and 60th day of the
Table 5 Heavy metal analysis of compost in Solan (H.P)

\begin{tabular}{|c|c|c|c|c|c|}
\hline Sr. no. & Parameter (mg/Kg) & 20th day & 40th day & 60th day & FCO standards \\
\hline 1. & Lead & $13.25 \pm 0.03$ & $9.93 \pm 0.82$ & $8.01 \pm 1.22$ & 100 \\
\hline 2. & Zinc & $7.62 \pm 1.82$ & $5.01 \pm 0.67$ & $4.29 \pm 1.33$ & 1000 \\
\hline 3. & Chromium & $2.92 \pm 0.12$ & $2.26 \pm 0.10$ & $1.85 \pm 1.24$ & 50 \\
\hline 4. & Cadmium & $1.32 \pm 0.22$ & $1.21 \pm 0.01$ & $1.18 \pm 0.12$ & 5 \\
\hline 5. & Copper & $7.12 \pm 2.12$ & $5.67 \pm 2.02$ & $2.12 \pm 1.42$ & 500 \\
\hline 6. & Nickel & $24.02 \pm 1.33$ & $23.12 \pm 0.67$ & $21.78 \pm 1.87$ & 50 \\
\hline
\end{tabular}


composting process, respectively, and for Mandi region of Himachal Pradesh that has been found lesser than the minimum value of the FCO standards. In this context, the parameters including magnesium and total organic carbon were observed decreasing up to 60th day of the composting process which has attributed to the liberation of the carbon dioxide and methane gas, whereas calcium goes on increasing with the degradation process that proves beneficial for the compost manufacturing process. The $\mathrm{C} / \mathrm{N}$ ratio of the municipal solid waste compost is an indication about the maturity level of the compost material which was observed $29.28 \%$ in the 20th day of composting, $28.91 \%$ in the 40th day of composting and $26.02 \%$ in the 60th day of composting period for Solan region, whereas it was found $30.01 \%$ in the 20th day of composting, $29.12 \%$ in the 40th day of composting and $28.32 \%$ in the 60th day of composting period for Mandi region, respectively, hence found more than the minimum criteria of the FCO (fertility control order) limits (Saha et al. 2010). The observations of the earlier studies of compost characterization in 59 cities of India described $\mathrm{C} / \mathrm{N}$ ratio range in between 7.2 and $36.5 \%$ that was quite high (Saha et al. 2010). Higher carbon/nitrogen content relatively more than $30 \%$ in the matured compost makes it unsuitable for use as fertilizer for the crop nourishment (Manohara et al. 2017).

\section{Heavy metal analysis}

The major parameters used for the heavy metal analysis are summarized in Tables 5, 6 for both Solan and Mandi study regions, respectively.

In general, it was observed from the tables that the concentrations of heavy metal of the compost produced from Solan exceeded that of Mandi but were within the prescribed FCO limits. Further, the evaluation of heavy metals analysis revealed that the compost samples from the Solan were rich in nickel and lead content as compared to other heavy metals due to the excessive amount of batteries and cells being found in the dumpsite as mix wastes and in comparison to Mandi study location. Chromium was found at lower concentrations at the maturation stage of the compost, i.e., at 60th day of the composting period reported as $1.85 \mathrm{mg} / \mathrm{kg}$ and $0.23 \mathrm{mg} / \mathrm{kg}$ for Solan and

Table 7 Classification of MSW compost for their marketability and use in different area (Mandal et al. 2014)

\begin{tabular}{|c|c|c|c|c|c|}
\hline Sr. no. & Class & FI & CI & Quality control compliance & Remarks \\
\hline 1. & A & $>3.5$ & $>4.0$ & Complying for heavy parameters & Best quality, low heavy metal, used for high value crops \\
\hline 2. & $\mathrm{~B}$ & $3.1-3.5$ & $>4.0$ & Complying for heavy parameters & Very good quality, medium fertilizing potential, low heavy metal \\
\hline 3. & $\mathrm{C}$ & $>3.5$ & $3.1-4.0$ & Complying for heavy parameters & Good quality, high fertilizing potential, medium heavy metal \\
\hline 4. & $\mathrm{D}$ & $3.1-3.5$ & $3.1-4.0$ & Complying for heavy parameters & Medium quality, medium fertilizing potential, medium heavy metal \\
\hline 5. & RU-1 & $<3.1$ & - & Complying for heavy parameters & $\begin{array}{l}\text { Low fertilizing potential; should not be allowed to market, only used as } \\
\text { soil conditioner }\end{array}$ \\
\hline 6. & RU-2 & $>3.5$ & $>4.0$ & Not complying for heavy parameters & $\begin{array}{l}\text { Restricted use; should not be allowed to market, used only for growing } \\
\text { non-food crops }\end{array}$ \\
\hline 7. & RU-3 & $>3.5$ & - & Not complying for heavy parameters & $\begin{array}{l}\text { Restricted use; should not be allowed to market, used only for develop- } \\
\text { ing lawns/gardens }\end{array}$ \\
\hline
\end{tabular}

Table 8 Comparison of 'Fertility Index' and 'Clean Index' of compost material of study regions with compost of Okhla plant, Delhi

\begin{tabular}{|c|c|c|c|c|c|c|c|}
\hline & \multicolumn{2}{|c|}{$\begin{array}{l}\text { 20th day of compost- } \\
\text { ing }\end{array}$} & \multicolumn{2}{|c|}{$\begin{array}{l}\text { 40th day of compost- } \\
\text { ing }\end{array}$} & \multicolumn{3}{|c|}{ 60th day of composting } \\
\hline & Solan & Mandi & Solan & Mandi & Solan & Mandi & $\begin{array}{l}\text { Delhi (Man- } \\
\text { dal et al. } \\
\text { 2014) }\end{array}$ \\
\hline Fertility Index & 3.5 & 3.5 & 3.5 & 3.6 & 3.5 & 3.6 & 4.54 \\
\hline Clean Index & 4.0 & 5.0 & 4.0 & 5.0 & 4.0 & 5.0 & 2.60 \\
\hline
\end{tabular}

Table 9 Comparison of 'Fertility Index' and 'Clean Index' of compost material of study regions with compost of Okhla plant, Delhi

\begin{tabular}{|c|c|c|c|c|c|c|c|}
\hline & \multicolumn{2}{|c|}{$\begin{array}{l}\text { 20th day of com- } \\
\text { posting }\end{array}$} & \multicolumn{2}{|c|}{$\begin{array}{l}\text { 40th day of com- } \\
\text { posting }\end{array}$} & \multicolumn{3}{|c|}{ 60th day of composting } \\
\hline & Solan & Mandi & Solan & Mandi & Solan & Mandi & Delhi (Mandal et al. 2014) \\
\hline Compost Class & Class D & Class B & Class D & Class A & Class D & Class A & - \\
\hline
\end{tabular}




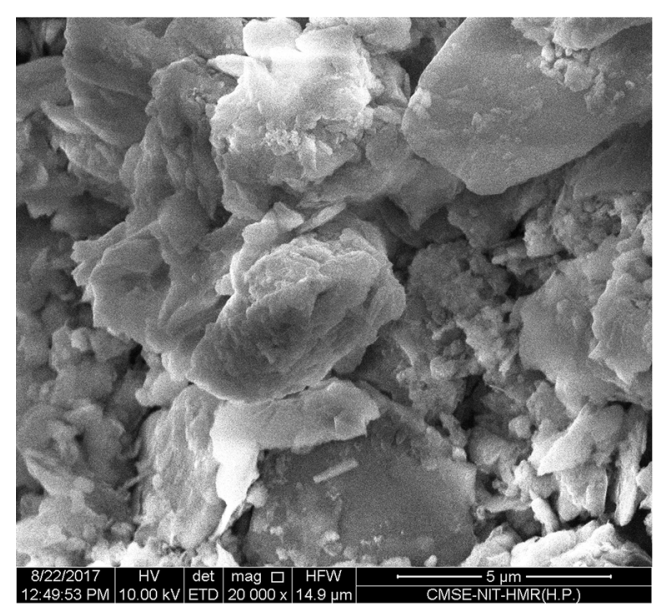

(a)

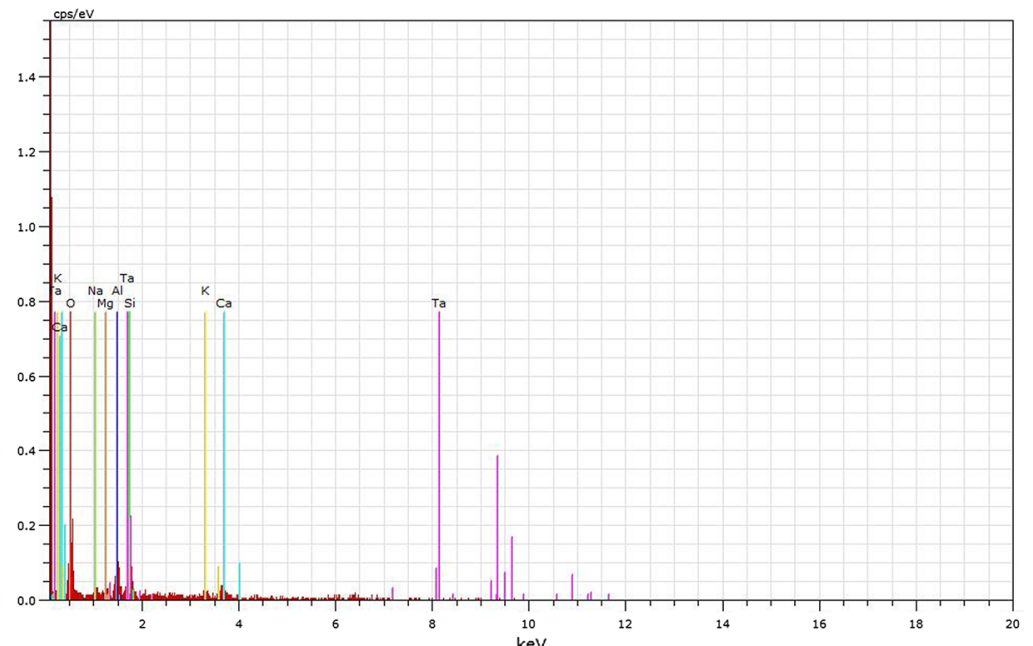

(b)

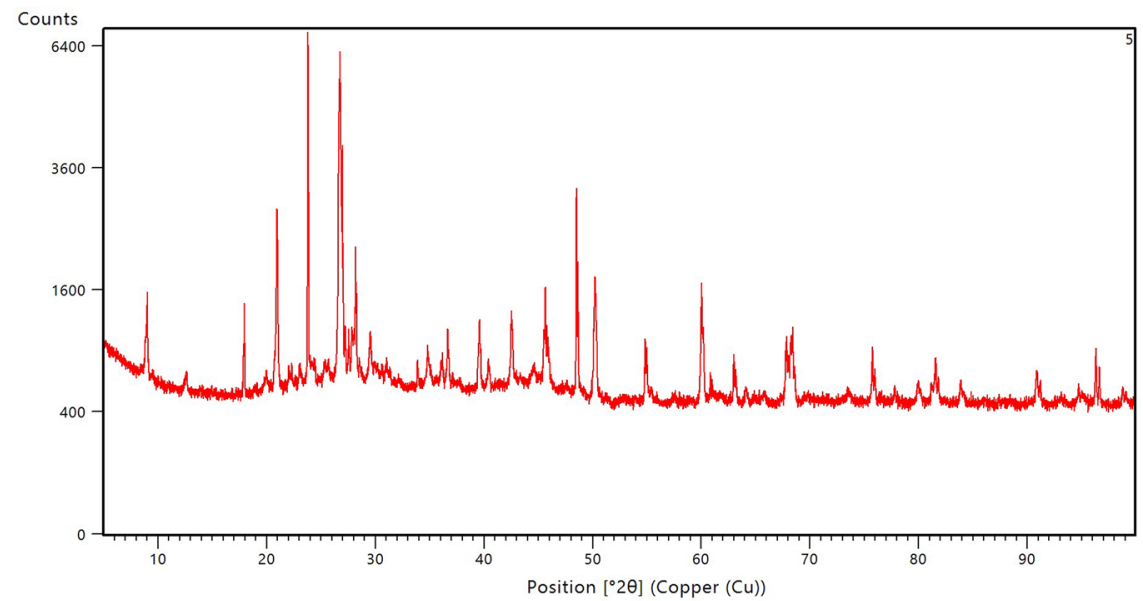

(c)

Fig. 2 SEM, EDS and XRD analyses of 20th day compost (Solan region)

Mandi regions, respectively. Similarly, cadmium concentration was observed $1.18 \mathrm{mg} / \mathrm{kg}$ at the maturation stage of the compost for Solan region and the same was found below detection levels for Mandi region. The heavy metal concentration of the municipal solid waste compost was found within the permissible limits as prescribed by fertility control order standards (FCO). Further, it was observed that the heavy metal concentration decreased with the increase in composting period and is similar to the pattern as reported earlier (Manohara and Belagali 2016). The reported literature reported comparatively lesser value of cadmium content at the maturation stage of the compost samples in the compost plant of Mysore city, i.e., $0.01 \mathrm{mg} / \mathrm{l}$ (Kiran and Srikantaswamy 2014). However, the average content of heavy metals in the compost material prepared in Indian cities was comparatively low than the compost material prepared in USA and European countries
(Saha et al. 2010). Higher the concentration of heavy metals signifies greater polluting potential of the compost and lesser value of clean index (CI).

\section{Fertility index and clean index}

The fertility index (FI) and clean index (CI) of the compost are quality-based parameters for determining the gradation of compost which determines its market value. To summarize, there are total seven classes of compost quality classification including A, B, C, D, RU-1, RU-2 and RU-3 based on the determination FI and CI. The four classes A-D depicted good quality compost and have good market value and can be used for organic farming and high value crops. The remaining classes are having restricted usage and cannot be applied for organic farming. The classification of MSW 


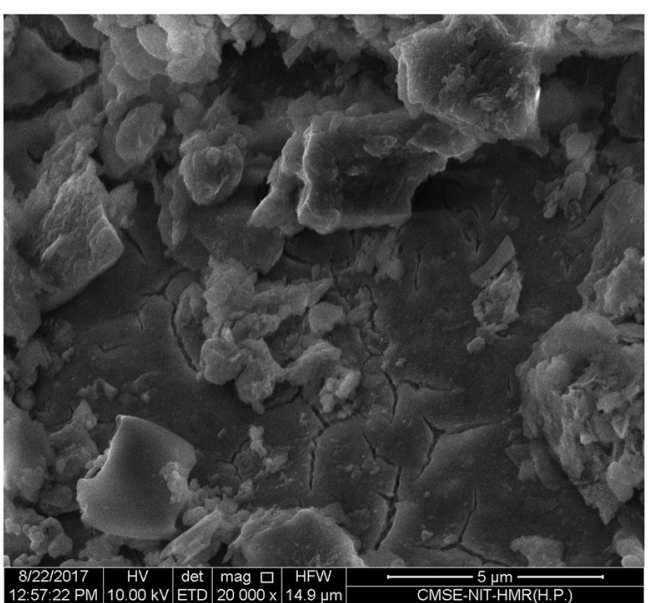

(a)

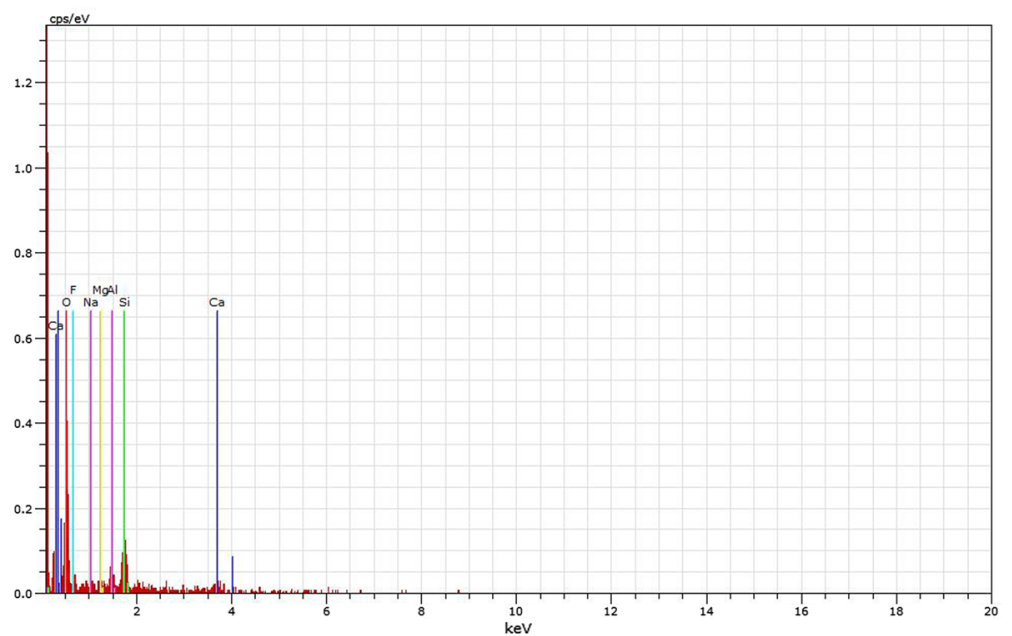

(b)

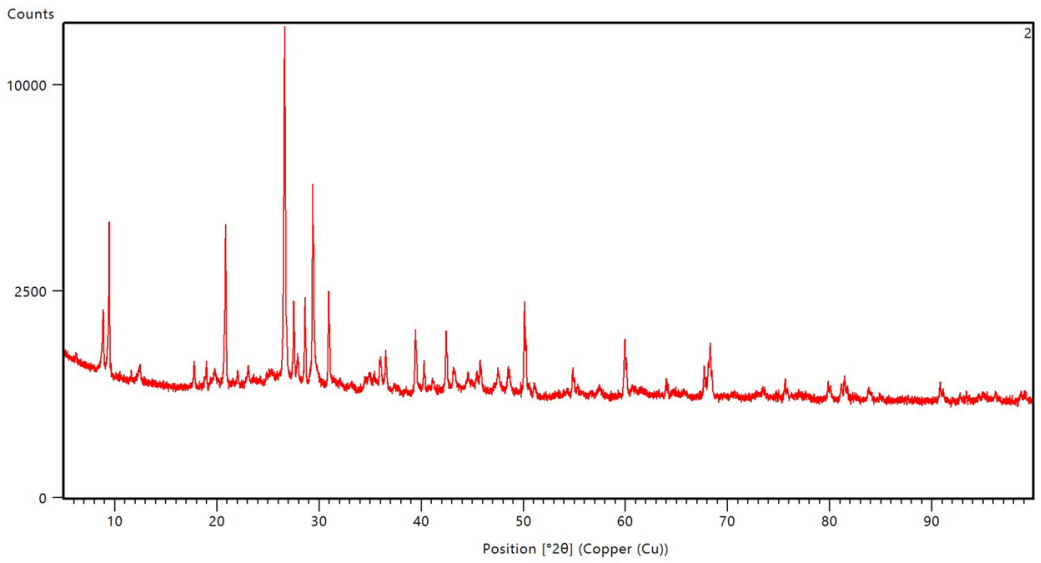

(c)

Fig. 3 SEM, EDS and XRD analyses of 40th day compost (Solan region)

compost for their marketability and use in different areas is shown in Table 7.

The criteria for 'weighing factor' to heavy metal parameters and 'score value' to compost for the evaluation of fertility index and clean index for both the study locations are presented in Tables S1-S12 of supplementary material. Further, a compost quality evaluator software (Saha et al. 2010) based on the MS excel blueprint has also been utilized to check the results obtained. The FI determined after 20th, 40th and 60th day of sampling of compost at the study location was 3.5. It was observed that the FI of compost generated at the Solan study location was similar for all of the sampling period. This signifies that primary degradation of the waste occurs by 20th day

The FI value for compost generated from Solan (3.5) can be categorized as Class $D$ as outlined by FCO standard and description mentioned in Table 7 for samples tested after full maturation (60th day). Similarly, the FI values for compost generated at Mandi site were determined to be 3.5 and
3.6 for samples tested after 20th day and for both 40th and 60th day. Hence, the compost can be categorized as Class $\boldsymbol{A}$ after full maturation period. Similarly, the CI value of the compost samples was determined to be 4.0 and 5.0 for Solan and Mandi study locations, respectively, for all the sampling periods. The compost generated at the study locations meets the specified criteria as per FCO standards since the determined heavy metal concentrations are less than the FCO standards. Different FI and CI values are summarized in Table 8 and the classification of compost category is shown in Table 9.

The results obtained from our study locations were compared with the compost generated at Okhla compost plant in Delhi, wherein the determined FI and CI values were 4.54 and 2.60 (Mandal et al. 2014), respectively. This revealed that the compost generated at the Okhla compost plant in Delhi was of poor quality due to high concentration of heavy metals and hence can be classified for Restricted Usage (RU 3). 


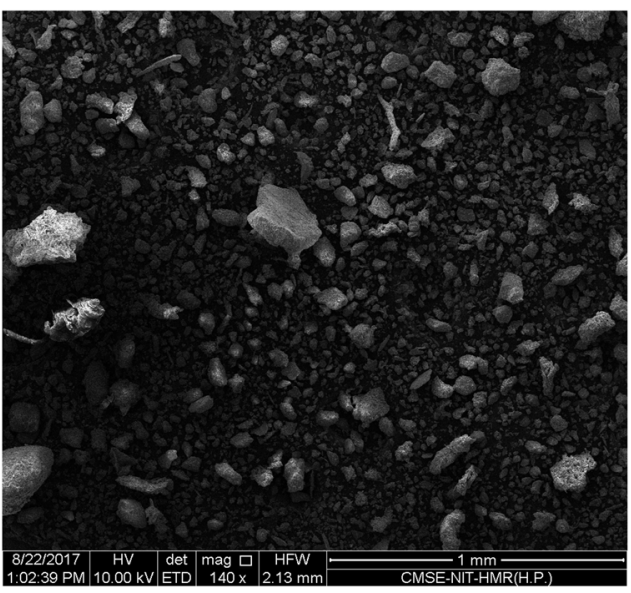

(a)

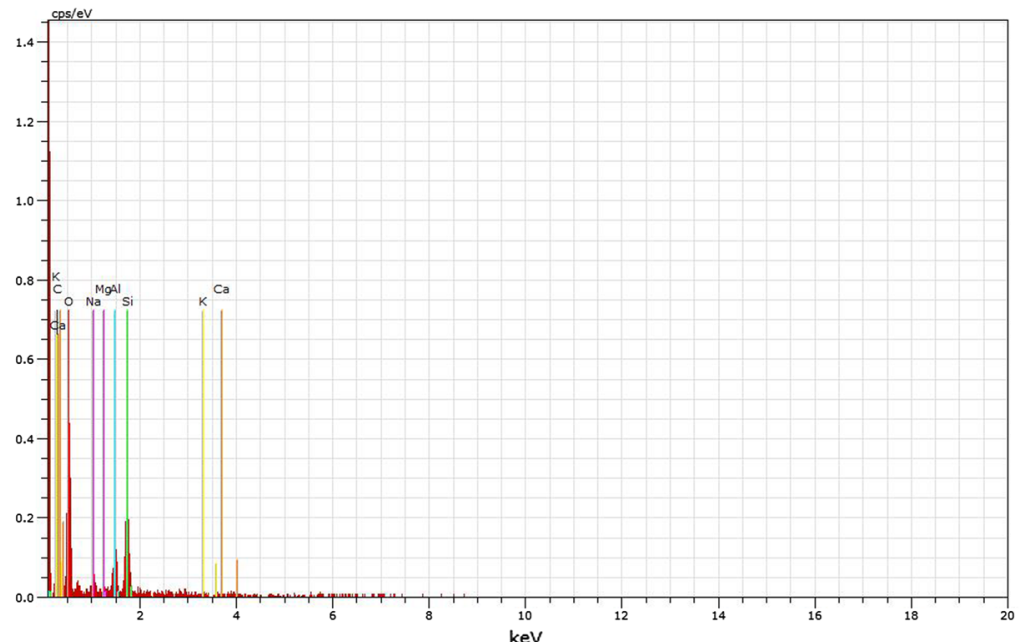

(b)

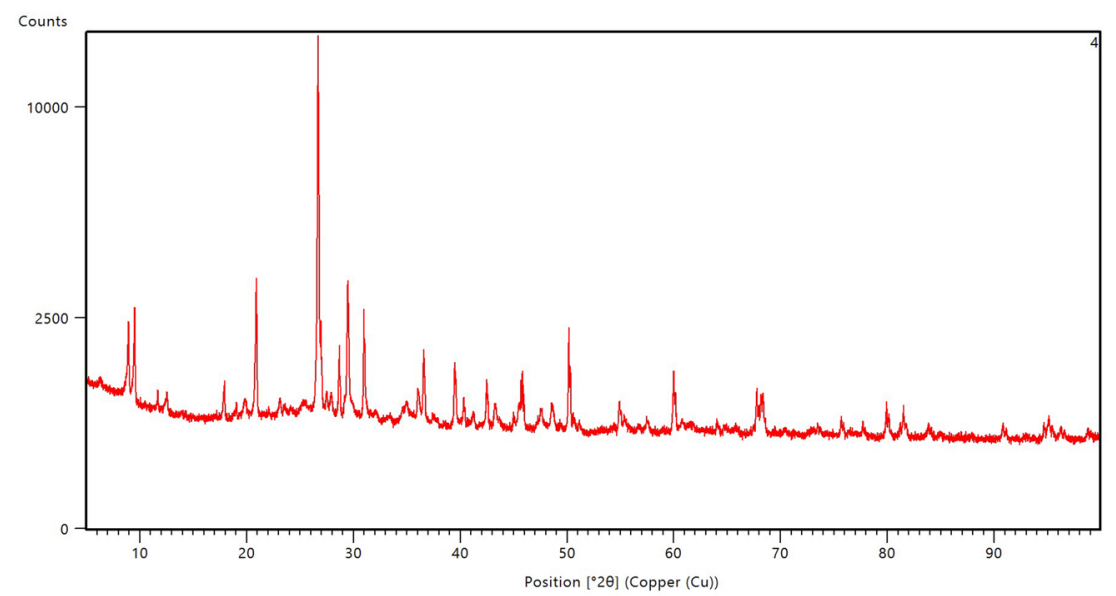

(c)

Fig. 4 SEM, EDS and XRD analyses of 60th day compost (Solan region)

To summarize, the mature compost generated at Solan study location is of medium quality having medium fertilizing and pollution potential and hence may be used for producing livestock for non-food crops. For, the compost generated from Mandi site, it can be classified as class A having very high fertilizing potential and low heavy metal content and hence suitable for growth of livestock of food crops.

\section{SEM-EDS analysis of compost material}

The SEM micrographs show the physical changes occurring during various stages of microbial degradation of municipal solid waste compost of both the study regions (Solan and Mandi) for 20th day, 40th day and 60th day of degradation process and are shown in Figs. 2(a, b), 3, 4, 5, 6, 7(a, b), whereas XRD analysis of compost samples is shown in Fig. 2(c), 3, 4, 5, 6, 7(c).

From the images obtained by SEM-EDS analysis for both the study regions, it is observed that in the time frame of the composting process from 1 to 20 days, the morphology showed a larger-sized solid material with smaller voids created on the surface. With the increase in time (20-40 days) and increased degradation process, the particle size started to reduce and finally after the complete degradation process (60th day), the particles were converted into smaller-sized solid particles with increase the voids on the surface indicating the formation of mature compost. This was observed for both the study locations

The electron dispersive spectroscopy (EDS) of the compost sample in Solan showed the presence of eight natural elements, namely oxygen, silicon, carbon, aluminum, sodium, calcium, potassium and magnesium (Table 10). 


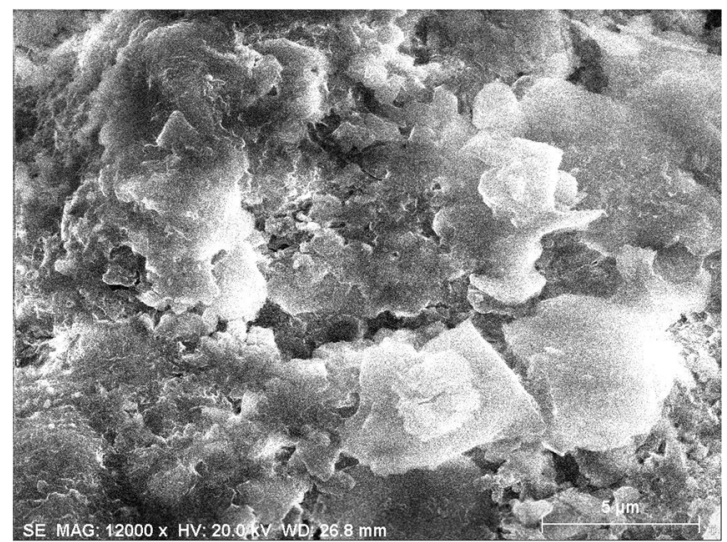

(a)

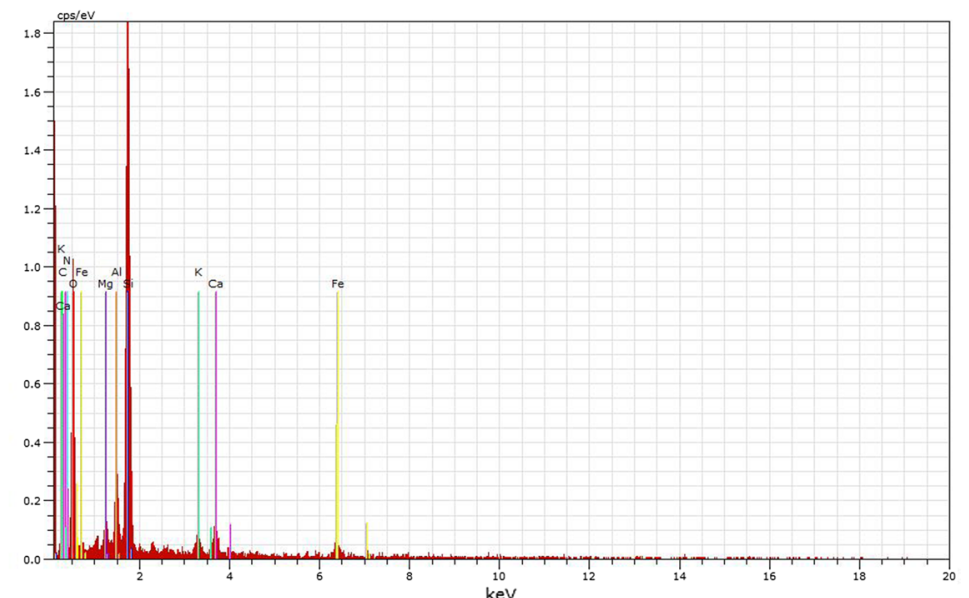

(b)

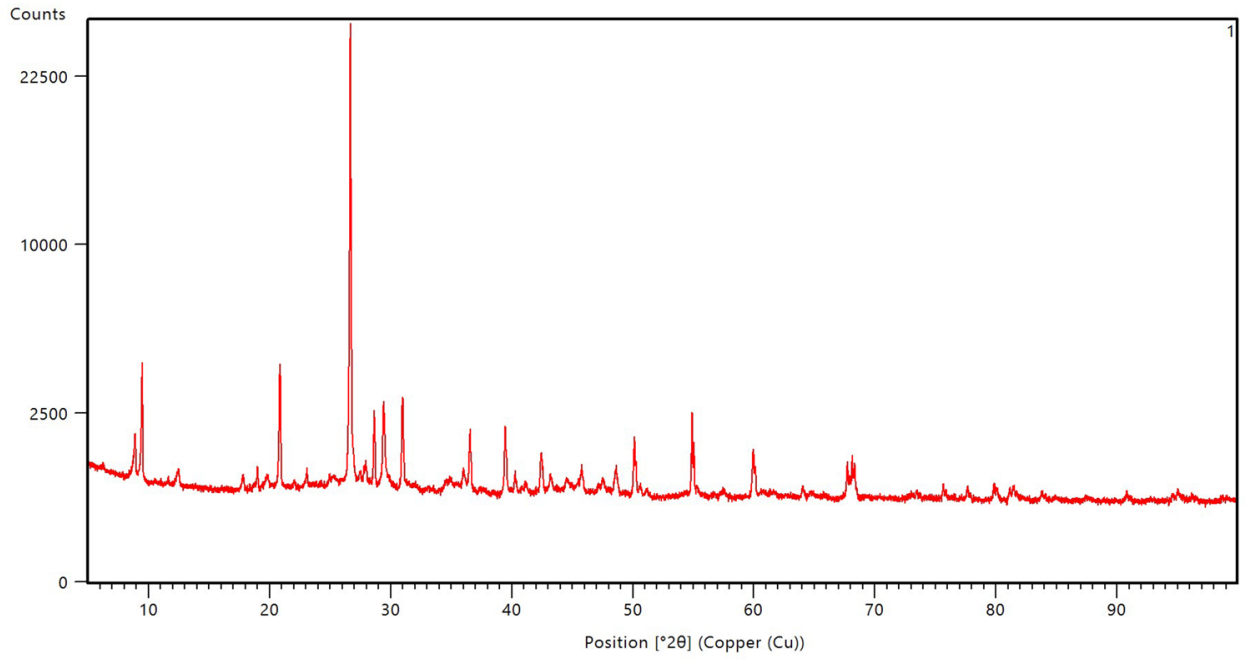

(c)

Fig. 5 SEM, EDS and XRD analyses of 20th day compost (Mandi region)

The concentration of oxygen was determined to be relatively higher $(60.35 \%)$ in comparison to other elements. The carbon fraction was determined to be $16.19 \%$ for samples collected on the 60th day of degradation process of compost when analyzed through EDS whereas the organic carbon content was found to be $14.22 \%$ by the Walkley method. In this context, it is revealed that out of total carbon percentage in the municipal solid waste compost samples, the maximum amount is observed as organic carbon fraction. A similar electron dispersive spectroscopy analysis was carried out on the compost samples from Mandi region and was reported to have the eight elements including oxygen, carbon, silicon, aluminum, potassium, calcium, sodium and iron (Table 11).

However, the oxygen fraction $(54.53 \%)$ for the samples analyzed for 60th day sampling period was less than observed for the samples from Solan study area.
Interestingly, a higher proportion of carbon content was reported for compost samples from Mandi being determined as $28.71 \%$ on the 60 th day of degradation process of compost, whereas the organic carbon content was found $12.46 \%$ by Walkley method because out of total carbon fraction, the percentage of organic carbon was observed more in the sample. The percentage of organic carbon in the compost sample of Mandi region was found slightly less than the organic carbon in the compost sample of Solan region. This was due to the reason that the organic matter has been observed more in the municipal solid waste of Solan region than Mandi region. The sufficient amount of oxygen and carbon promotes the aerobic composting of the waste carried out in both of the study locations. 


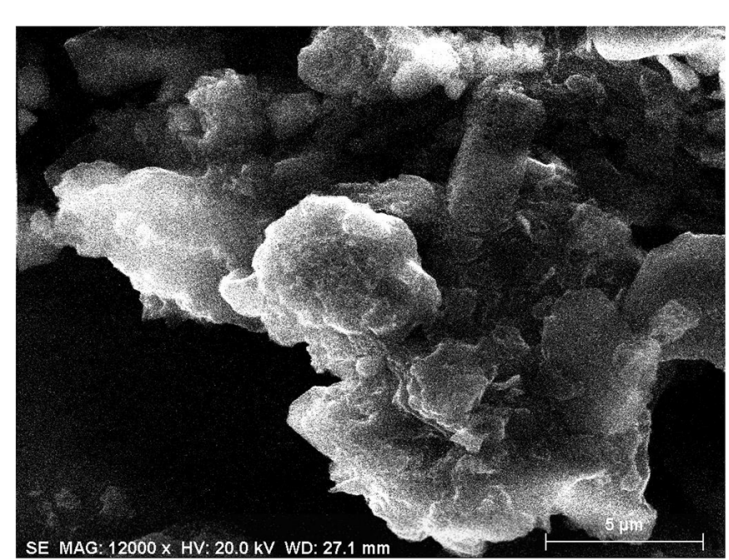

(a)

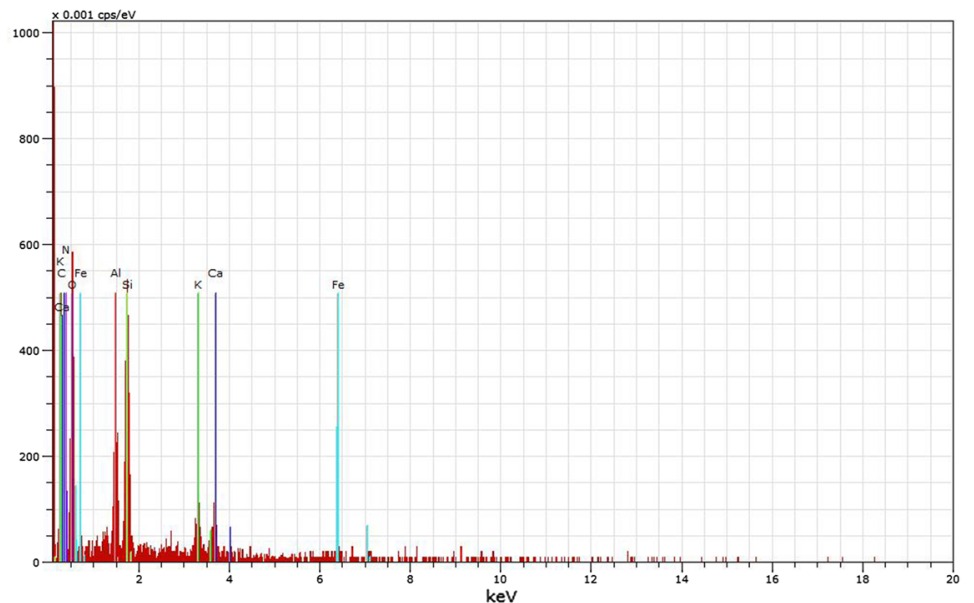

(b)

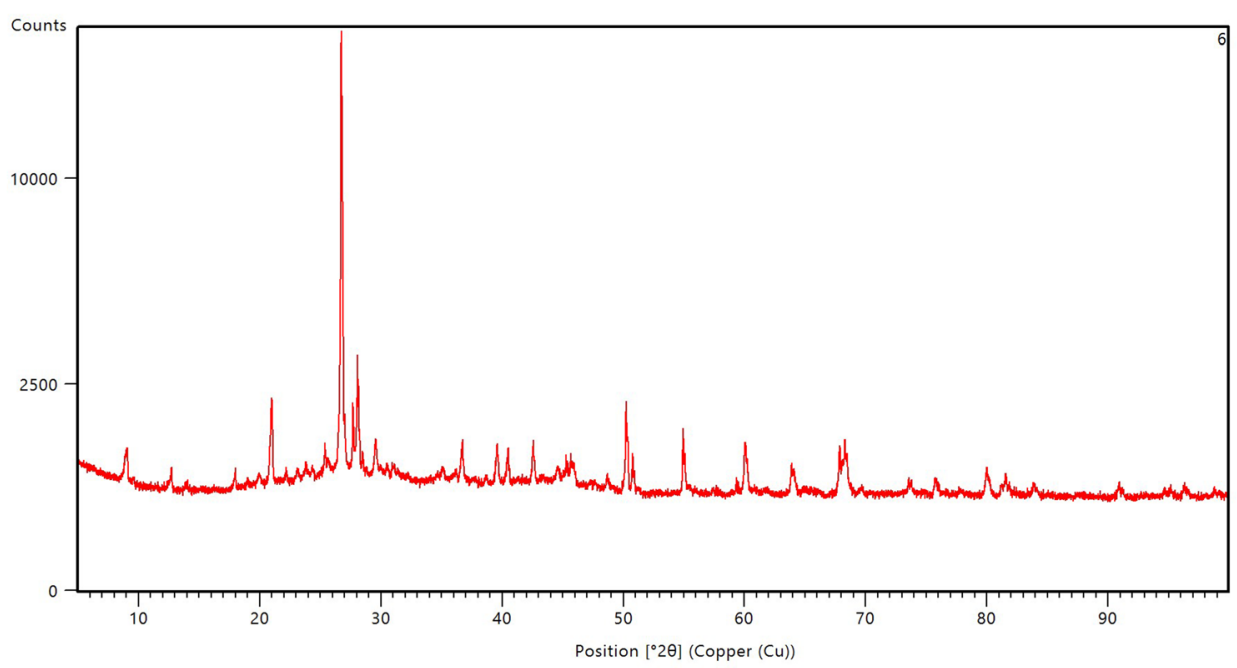

(c)

Fig. 6 SEM, EDS and XRD analyses of 40th day compost (Mandi region)

\section{XRD analysis of compost material}

XRD analysis of compost material for three decomposition stages in the Solan region and Mandi region of Himachal Pradesh is shown in Figs. 2(c), 3, 4, 5, 6, 7(c) (presented in above section). X-Ray diffraction is the useful tool to get the structural information of any compound (Kiran and Srikantaswamy 2014). In particular, each signal in XRD represents the plane of a crystal. The spectra of composting piles of both study regions revealed acute peaks for composting samples collected on 20th day. Subsequent collected samples on 40th and 60th day at both the study locations showed the reduced number of these peaks due to increase in degradation process leading to formation of mature compost. The intense peaks appearing on the spectra of XRD analysis of compost material revealed the presence of some major compounds including calcium carbonate, calcium thallium nitride, silicon oxide, niobium sulfide and zinc sulfide and minerals including quartz, calcite and dolomite. The presence of minerals including quartz, calcite, and dolomite was due to the disposal of mix waste in the dumping site. The presence of inert materials, sand, grit, egg shells, and green waste was attributed minerals in the municipal solid waste compost samples. From the overall data obtained from the $\mathrm{X}$-ray diffraction spectra, it is clear that particle size of solid waste decreases during the degradation process of the compost material.

In this context, the results of scanning electron microscopy of compost samples from both the regions (Mandi and Solan) revealed that with the starting phase of degradation process up to the 60th day of degradation process of compost, the large-sized particles were converted into smaller particles showing maturation of the compost, whereas XRD spectra also indicated the sharp peaks of minerals at the 


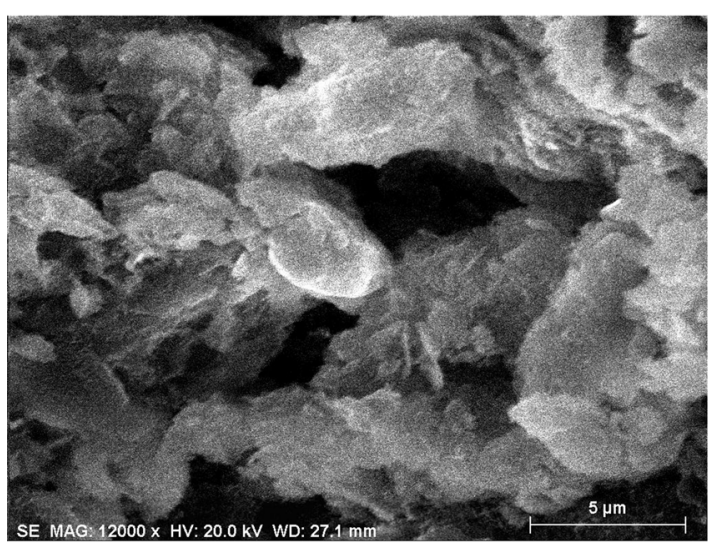

(a)

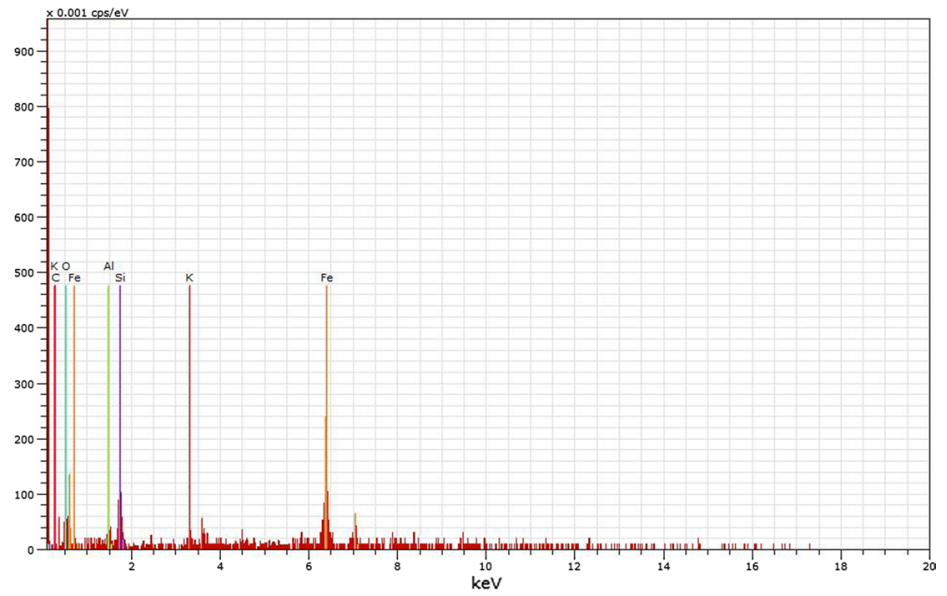

(b)

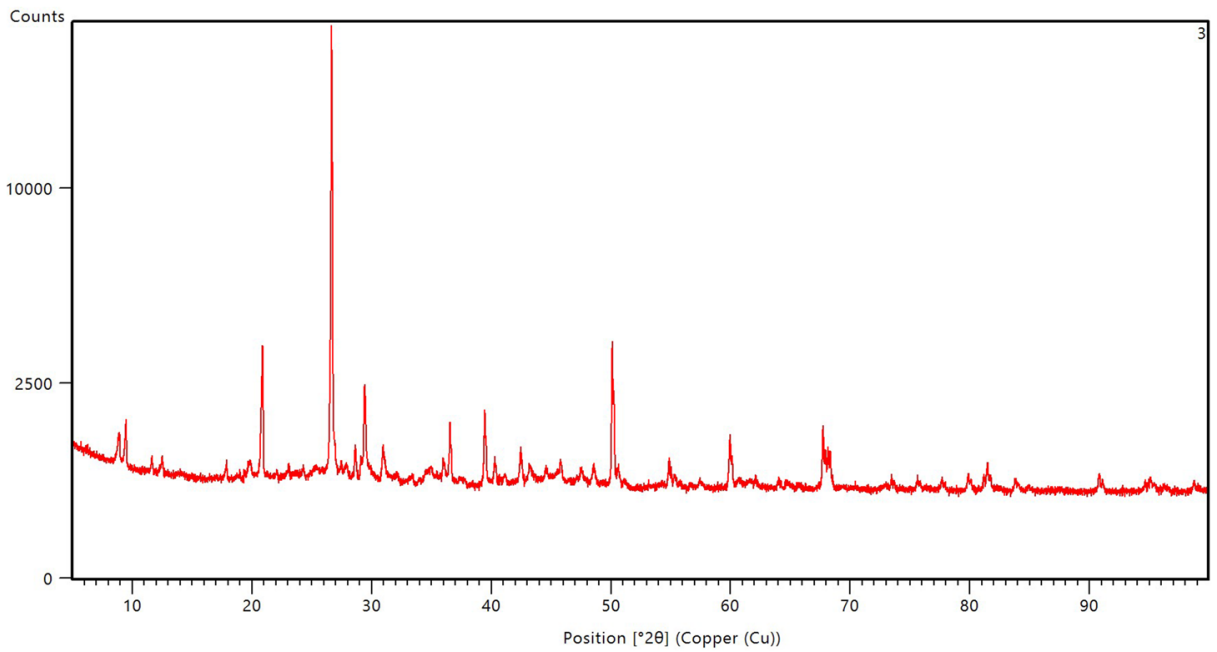

(c)

Fig. 7 SEM, EDS and XRD analyses of 60th day compost (Mandi region)

starting degradation phase of compost and up to the 60th day of degradation process; very few peaks were shown in the spectra revealed breakdown of particles and indicate matured compost. The results obtained from XRD are having good collaboration with the SEM analysis of compost samples.

\section{Discussion on compost generation in state of Himachal Pradesh}

The MSW generated in Himachal Pradesh has a high proportion of biodegradables which can be easily generated into compost and can be used as a natural fertilizer. However, the existing scenario of waste management is not very satisfactory in Himachal Pradesh (Sharma et al. 2018). Previous literature studies (Saha et al. 2010) have reported the practice of composting in regions of Kullu, Solan, Shimla and Manali in Himachal Pradesh. Though the type of feedstock use was different, some composting practices were in use at the time of reported literature by Saha et al. 2010. At the time of the reported study of Saha et al. 2010, the municipalities of respective regions had received and utilized funds for the construction of composting yards but the efforts to make compost were not very successful. The reasons for discontinuation of composting at the study locations reported by Saha et al. 2010 are manifold with major reasons being failure to implement complete and proper segregation process at Kullu and Manali study location leading to generation of poor quality compost (Personal Communication with an official of Municipal Corporation Shimla). The reason for discontinuation of composting process in Shimla is due to non-availability of land to meet the increased MSW generated and hence the more preferred treatment of MSW is to burn them in Refuse Derived Fuel (RDF) plant as it leads to immediate reduction of waste (Personal Communication with an official of Municipal Corporation Shimla). Other 
Table 10 SEM quantitative analysis of detected elements in 20th, 40th, 60th days (Solan region)

\begin{tabular}{|c|c|c|c|c|c|c|c|}
\hline Sr. no. & Element & $\begin{array}{l}\text { Atomic } \\
\text { number }\end{array}$ & Series & $\begin{array}{l}\text { Un-normalized } \\
\text { weight }\end{array}$ & $\begin{array}{l}\text { Normalized } \\
\text { weight }\end{array}$ & Atomic (\%) & Error \\
\hline \multicolumn{8}{|c|}{ 20th day of composting } \\
\hline 1. & $\mathrm{O}$ & 8 & $\mathrm{~K}$ & 20.66 & 45.96 & 64.55 & 6.20 \\
\hline 2. & $\mathrm{Si}$ & 14 & $\mathrm{~K}$ & 8.33 & 18.53 & 14.83 & 0.70 \\
\hline 3. & $\mathrm{Al}$ & 13 & $\mathrm{~K}$ & 4.70 & 10.47 & 8.72 & 0.50 \\
\hline 4. & $\mathrm{Ca}$ & 20 & $\mathrm{~K}$ & 4.60 & 10.23 & 5.74 & 0.60 \\
\hline 5. & $\mathrm{Ta}$ & 73 & M & 3.06 & 6.80 & 0.84 & 0.40 \\
\hline 6. & $\mathrm{~K}$ & 19 & $\mathrm{~K}$ & 2.74 & 6.09 & 3.50 & 0.40 \\
\hline 7. & $\mathrm{Na}$ & 11 & $\mathrm{~K}$ & 0.46 & 1.03 & 1.01 & 0.10 \\
\hline 8. & $\mathrm{Mg}$ & 12 & $\mathrm{~K}$ & 0.40 & 0.81 & 0.82 & 0.10 \\
\hline \multicolumn{8}{|c|}{ 40th day of composting } \\
\hline 1. & $\mathrm{O}$ & 8 & $\mathrm{~K}$ & 33.71 & 62.10 & 73.10 & 8.60 \\
\hline 2. & $\mathrm{Si}$ & 14 & $\mathrm{~K}$ & 10.13 & 18.63 & 12.49 & 0.80 \\
\hline 3. & $\mathrm{~F}$ & 9 & $\mathrm{~K}$ & 3.68 & 6.77 & 6.71 & 2.60 \\
\hline 4. & $\mathrm{Ca}$ & 20 & $\mathrm{~K}$ & 2.96 & 5.44 & 2.56 & 0.50 \\
\hline 5. & $\mathrm{Al}$ & 13 & $\mathrm{~K}$ & 2.60 & 4.78 & 3.33 & 0.30 \\
\hline 6. & $\mathrm{Mg}$ & 12 & $\mathrm{~K}$ & 0.70 & 1.28 & 0.99 & 0.20 \\
\hline 7. & $\mathrm{Na}$ & 11 & $\mathrm{~K}$ & 0.54 & 0.99 & 0.81 & 0.20 \\
\hline \multicolumn{8}{|c|}{ 60th day of composting } \\
\hline 1. & $\mathrm{O}$ & 8 & $\mathrm{~K}$ & 38.71 & 53.32 & 60.35 & 9.70 \\
\hline 2. & $\mathrm{Si}$ & 14 & $\mathrm{~K}$ & 15.70 & 21.63 & 13.94 & 1.10 \\
\hline 3. & $\mathrm{C}$ & 6 & $\mathrm{~K}$ & 7.80 & 10.74 & 16.19 & 4.70 \\
\hline 4. & $\mathrm{Al}$ & 13 & $\mathrm{~K}$ & 6.16 & 8.49 & 5.70 & 0.60 \\
\hline 5. & $\mathrm{Na}$ & 11 & $\mathrm{~K}$ & 2.30 & 3.17 & 2.50 & 0.40 \\
\hline 6. & $\mathrm{Ca}$ & 20 & $\mathrm{~K}$ & 0.92 & 1.26 & 0.57 & 0.30 \\
\hline 7. & $\mathrm{~K}$ & 19 & $\mathrm{~K}$ & 0.74 & 1.02 & 0.47 & 0.20 \\
\hline 8. & $\mathrm{Mg}$ & 12 & $\mathrm{~K}$ & 0.27 & 0.37 & 0.27 & 0.10 \\
\hline
\end{tabular}

proposed reasons for discontinuation of the composting process in Himachal Pradesh are due to poor segregation, uneconomic viability of compost generated, lack of funding and lack of manpower (Personal Communication with an official of Municipal Corporation Shimla).

At the time of carrying out the present study, two compost pits were under working condition in Solan and Mandi locations but these plants have also presently stopped their composting process due to their non-economic viability. This is an alarming trend in the state that the once existing composting system is gradually losing its way. The reasons for closure of the composting units in Solan were its geographical issue (dumpsite being located adjacent to National Highway), breakdown in communication of functioning of the plant under public-private partnership (PPP), non-economic feasibility of compost generated and lack of funds for smooth operation of the plant. For the Mandi site, the major reason for closure of the plant was the lack of availability for the operation of the compost plant. As observed from our study, the compost generated in this study location is of very high quality. Apart from this, currently the RDF plant has been installed in the dumpsite of Shimla for the processing of biodegradable waste which is under working condition.

\section{Conclusion}

Physical characterization of the municipal solid waste in Himachal Pradesh revealed that the municipal solid waste is rich in organic waste. Hence, composting is a suitable option for the management of organic fraction of the waste because it is highly cost effective and can be used as fertilizer for plants and help in reduction of waste burden from dumpsites. It is observed from the present study that majority of the physico-chemical parameters of municipal solid waste compost except moisture content, electrical conductivity and total organic carbon were well within the range of permissible limits of FCO. The concentration of heavy metals at the initial stage of degradation of organic matter was on higher side but with the increase in time and completion of the process a decrease in heavy metal concentrations were observed. Apart from this, the analysis of fertility index and clean index revealed that the compost 
Table 11 SEM quantitative analysis of detected elements in 20th, 40th, 60th days (Mandi region)

\begin{tabular}{|c|c|c|c|c|c|c|c|}
\hline Sr. no. & Element & $\begin{array}{l}\text { Atomic } \\
\text { number }\end{array}$ & Series & $\begin{array}{l}\text { Un-normalized } \\
\text { weight }\end{array}$ & $\begin{array}{l}\text { Normalized } \\
\text { weight }\end{array}$ & Atomic (\%) & Error \\
\hline \multicolumn{8}{|c|}{ 20th day of composting } \\
\hline 1. & $\mathrm{O}$ & 8 & $\mathrm{~K}$ & 54.13 & 46.24 & 47.66 & 10.0 \\
\hline 2. & $\mathrm{C}$ & 6 & $\mathrm{~K}$ & 30.03 & 25.66 & 35.23 & 7.70 \\
\hline 3. & $\mathrm{Si}$ & 14 & $\mathrm{~K}$ & 19.03 & 16.26 & 9.55 & 0.90 \\
\hline 4. & $\mathrm{Al}$ & 13 & $\mathrm{~K}$ & 3.26 & 2.78 & 1.70 & 0.30 \\
\hline 5. & $\mathrm{~N}$ & 7 & M & 3.10 & 2.64 & 3.11 & 2.20 \\
\hline 6. & $\mathrm{Fe}$ & 26 & $\mathrm{~K}$ & 2.56 & 2.19 & 0.65 & 0.20 \\
\hline 7. & $\mathrm{Ca}$ & 20 & $\mathrm{~K}$ & 2.28 & 1.95 & 0.80 & 0.20 \\
\hline 8. & $\mathrm{Mg}$ & 12 & $\mathrm{~K}$ & 1.54 & 1.31 & 0.89 & 0.20 \\
\hline 9. & $\mathrm{~K}$ & 19 & $\mathrm{~K}$ & 1.12 & 0.96 & 0.40 & 0.1 \\
\hline \multicolumn{8}{|c|}{ 40th day of composting } \\
\hline 1. & $\mathrm{Fe}$ & 26 & $\mathrm{~K}$ & 16.03 & 47.84 & 23.32 & 1.30 \\
\hline 2. & $\mathrm{O}$ & 8 & $\mathrm{~K}$ & 8.35 & 24.90 & 42.37 & 5.00 \\
\hline 3. & $\mathrm{Si}$ & 14 & $\mathrm{~K}$ & 4.03 & 12.03 & 11.66 & 0.50 \\
\hline 4. & $\mathrm{C}$ & 6 & $\mathrm{~K}$ & 2.20 & 6.56 & 14.86 & 4.10 \\
\hline 5. & $\mathrm{Al}$ & 13 & $\mathrm{~K}$ & 1.88 & 5.62 & 5.67 & 0.30 \\
\hline 6. & $\mathrm{~K}$ & 19 & $\mathrm{~K}$ & 1.02 & 3.06 & 2.13 & 0.20 \\
\hline \multicolumn{8}{|c|}{ 60th day of composting } \\
\hline 1. & $\mathrm{O}$ & 8 & $\mathrm{~K}$ & 47.15 & 51.50 & 54.53 & 12.40 \\
\hline 2. & $\mathrm{C}$ & 6 & $\mathrm{~K}$ & 18.64 & 20.36 & 28.71 & 8.50 \\
\hline 3. & $\mathrm{Si}$ & 14 & $\mathrm{~K}$ & 9.88 & 10.80 & 6.51 & 0.60 \\
\hline 4. & $\mathrm{Al}$ & 13 & $\mathrm{~K}$ & 6.24 & 6.82 & 4.28 & 0.50 \\
\hline 5. & $\mathrm{~K}$ & 19 & $\mathrm{~K}$ & 3.06 & 3.34 & 1.45 & 0.30 \\
\hline 6. & $\mathrm{Ca}$ & 20 & $\mathrm{~K}$ & 2.59 & 2.83 & 1.19 & 0.30 \\
\hline 7. & $\mathrm{Na}$ & 7 & $\mathrm{~K}$ & 2.02 & 2.21 & 2.67 & 2.90 \\
\hline 8. & $\mathrm{Fe}$ & 26 & $\mathrm{~K}$ & 1.97 & 2.16 & 0.65 & 0.30 \\
\hline
\end{tabular}

has restricted usage for marketability on the basis of fertility control order standards for Solan region, whereas the compost prepared in Mandi region lies within good quality compost with medium fertility potential and low heavy metal content, hence the prepared compost for Mandi region can be used for high value crops and its deliberated purposes. Further, the compost of Solan region has restricted usage in organic farming but it can be used for soil conditioner in laws and gardens, etc. The municipal solid waste compost of study region Solan cannot be used as fertilizer due to its low fertilizing potential. The concentration of heavy metal content for both the study regions has been found within the permissible limits of the fertility control order standards assigned by Ministry of Agriculture, Government of India. The SEM and XRD analyses revealed that during the degradation process, the breakdown of organic matter got started and towards the 60th day of degradation process, the compost got converted into small-sized solid particles, expanded the cavities on the surface of particles and finally indicated the maturation of compost. Hence, it is revealed from the study that aerobic composting is a worthy option for the processing of municipal solid waste as well as it can also reduce the weight of organic fraction in the dumpsite. To make the compost valuable and usable based on agricultural point of view; it necessitates proper segregation of municipal solid waste and proper treatment of compost prior to its application on land and utilized for high value food crops.

Acknowledgements The authors duly acknowledge the help received from Material Science Department of NIT Hamirpur, Himachal Pradesh 177005 and NIT Jalandhar 144011 for conducting the SEMEDS and XRD analyses of compost samples.

Open Access This article is distributed under the terms of the Creative Commons Attribution 4.0 International License (http://creativeco mmons.org/licenses/by/4.0/), which permits unrestricted use, distribution, and reproduction in any medium, provided you give appropriate credit to the original author(s) and the source, provide a link to the Creative Commons license, and indicate if changes were made.

\section{References}

Adefemi SO, Awokunmi EE (2009) The impact of municipal solid waste disposal in Ado Ekiti metropolis, Ekiti State, Nigeria. J Environ Sci Tech 3:186-189. https://doi.org/10.5897/AJEST09.075

ASTM D 5198-09 (2003) Standard practice for nitric acid digestion of solid waste. ASTM International, West Conshohocken, PA 
Bharti O, Singh A, Singh DP, Sood V (2014) Effective municipal solid waste management practices: a case study of Shimla, Himachal Pradesh, India. Waste Manag Res Uti 1:173-182

Bruun JM, Hansen TL, Christensen TH, Magid J, Jensena LS (2006) Application of processed organic municipal solid waste on agricultural land - scenario analysis. Environ Model Assess 11:251265. https://doi.org/10.1007/s10666-005-9028-0

CPCB (2010) Urban Waste Profile. Parivesh Bhavan, Delhi. Central Pollution Control Board, Ministry of Environment and Forests, Government of India, New Delhi. December, Newsletter. http:// cpcb.nic. Accessed 15 June 2018

FAI (2007) The Fertilizer Control Order 1985. The Fertilizer Association of India, New Delhi

Gomez G, Meneses M, Ballinas L, Castells F (2008) Characterization of urban solid waste in Chihuahua, Mexico. Waste Manag 28:2465-2471. https://doi.org/10.1016/j.wasman.2007.10.023

Gupta B, Arora SK (2016) Municipal solid waste management in Delhi-the Capital of India. Int J Innov Res Sci Eng Technol 5:5130-5138. https://doi.org/10.15680/IJIRSET.2016.0504106

Hancs A, Novak P, Dvorak M, Habart J, Svehla P (2011) Composition and parameters of household bio-waste in four seasons. Waste Manag 31:1450-1460. https://doi.org/10.1016/j.wasma n.2011.02.016

Hargreaves JC, Adl SM, Warman P (2007) A review of the use of composted municipal solid waste in agriculture. Agric Ecosyst Environ 123:1-14. https://doi.org/10.1016/j.agee.2007.07.004

Ingelmo F, Jose MM, Desamparados SM, Gallardo A, Lapen L (2012) Influence of organic matter transformations on the bioavailability of heavy metals in a sludge based compost. J Environ Manag 95:104-109. https://doi.org/10.1016/j.jenuman.2011.04.015

IS 10158 (1982) Methods of analysis of solid waste (Excluding industrial solid wastes), Bureau of Indian standards, New Delhi, India

IS 2720-26 (1986) Methods of tests for soils, bureau of Indian standards, New Delhi, India

Kiran BM, Srikantaswamy S (2014) Heavy metals assessment in municipal solid waste dumpsite, Mysore, Karnataka, India. Int J Adv Res Eng Tech 5:88-93. http://ww.iaeme.com/ijaret/IJARET

Kumar NK, Goel S (2009) Characterization of municipals solid waste and a proposed management plan for Kharagpur, West Bengal, India. Res Cons Rec 53:166-174. https://doi.org/10.1016/j.resco nrec.2008.11.004

Kumar S, Bhattacharyya JK, Vaidya AN, Chakrabarti T, Devotta S, Akolkar AB (2009) Assessment of the status of municipal solid waste management in metro cities, state capitals, class I cities, and class II towns in India: an insight. Waste Manag 29:883-895. https://doi.org/10.1016/j.wasman.2008.04.011

Malakahmad A, Idrus NB, Abulqumboz MS, Yavari S, Kutty SR (2017) In-vessel co-composting of yard waste and food waste: an approach for sustainable waste management in Cameron Highlands, Malasia. Int J Recycl Org Waste Agric 6:149-157. https:// doi.org/10.1007/s40093-017-0163-9

Mandal P, Chaturvedi MK, Bassin JK, Vaidya AN, Gupta RK (2014) Qualitative assessment of municipal solid waste compost by indexing method. Int J Recycl Org Waste Agric 3:133-139. https ://doi.org/10.1007/s40093-014-0075-X

Manohara B, Belagali SL (2016) Evaluation of energy dispersive scanning electron microscopy and X-ray fluorescence techniques for analysis of compost quality. R Soc Chem. https://doi.org/10.1039/ c6ay02586b

Manohara B, Belagali SL, Ragothama S (2017) Study of decomposition pattern during aerobic composting of municipal solid waste by physico-chemical and spectroscopic method. Int J Chem Tech Res 10:27-34. http://sphinxsai.com/2017/ch

Mazumdar NB (2007) Composting municipal solid waste: the Indian scenario. Int J Environ Technol Manag 7:326-350. https://doi. org/10.1504/IJETM.2007.015150
Mbuligwe SE, Kassenga GR, Kaseva ME, Chaggu EJ (2002) Potential and constraints of composting domestic solid waste in developing countries: findings from a pilot study in Dares Salaam, Tanzania. Res Con Rec 36:45-59. https://doi.org/10.1016/S0921 $-3449(02) 00009-5$

NEERI (2009) Assessment of quality of compost from waste processing plants of Calicut, Delhi and Jalandhar. Envir Engg Res Institute, Nagpur

Pandyaswargo AH, Gamaralalage D, Premakumara J (2014) Financial sustainability of modern composting: the economically optimal scale for municipal waste composting plant in developing Asia. Int J Recycl Org Waste Agric 3:66. https://doi.org/10.1007/s4009 3-014-0066-y

Puri A, Kumar M, Eonkar J (2008) Solid waste management in Jalandhar city and its impact on community health. Indian J Occup Environ Med 12:76-81. https://doi.org/10.4103/0019-5278.43265

Rana R, Ganguly R, Gupta AK (2018) Physico-chemical characterization of solid waste management from tricity region of northern India. J Mater Cycl Waste Manag 20(1):678-689. https://doi. org/10.1007/s10163-017-0615-3

Rawat M, Ramanathan AL, Kuriakose T (2013) Characterization of municipal solid waste compost (MSWC) from selected Indian cities - a case study for its sustainable utilization. J Envir Prot 4:163-171. https://doi.org/10.4236/jep.2013.42019

Saha JK, Panwar N, Singh MV (2010) An assessment of municipal solid waste compost quality produced in different cities of India in the perspective of developing quality control indices. Waste Manag 30:192-201. https://doi.org/10.1016/j.wasman.2009.09.041

Sarkar P, Chourasia R (2017) Bioconversion of organic solid wastes into biofortified compost using a microbial consortium. Int J Recycl Org Waste Agric 6:321-334. https://doi.org/10.1007/ s40093-017-0180-8

Sethi S, Kothiyal NC, Nema KA, Kaushik MK (2013) Characterization of municipal solid waste in Jalandhar City, Punjab, India. J Hazard Toxic Radioact Waste 17:97-106. https://doi.org/10.1016/(ASCE) HZ.2153-5515.0000156

Sharholy M, Ahmad K, Mahmood G, Trivedi RC (2008) Municipal solid waste management in Indian cities - a review. Waste Manag 28:459-467. https://doi.org/10.1016/j.wasman.2007.02.008

Sharma A, Ganguly R, Gupta AK (2017) Characterization of municipal solid waste in Sundernagar, Himachal Pradesh, India. Res J Pharm Bio Chem Sci 8:276. https://doi.org/10.4236/jep.2013.42019

Sharma A, Ganguly R, Gupta AK (2018) Matrix method for evaluation of existing solid waste management system in Himachal Pradesh, India. J Mater Cycl Waste Manag 20(3):1813-1831. https://doi. org/10.1007/s10163-018-0703-z

Shekdar AV (2009) Sustainable solid waste management: an integrated approach for Asian countries. Waste Manag 29:1438-1444. https ://doi.org/10.1016/j.wasman.2008.08.025

Srivastava R, Krishna V, Sonkar I (2014) Characterization and management of municipal solid waste: a case study of Varanasi City, India. Int J Curr Acad Rev 2(8):10-16

Sudharmaidevi CR, Thampatti KCM, Saifudeen N (2017) Rapid production of organic fertilizer from degradable waste by thermochemical processing. Int J Recycl Org Waste Agric 6:1-11. https ://doi.org/10.1007/s40093-016-0147-1

TERI (2015) Urban waste management in Himachal Pradesh. http:// www.teriin.org/projects/green/pdf/HP-Waste-management.pdf. Accessed 3 Oct 2018

USEPA 1995. A guide to the bio-solids risk assessments for the EPA, Part 503 Rule, United State Environmental Protection Agency, office of waste water management EPA/832-B-93-005-144

Publisher's Note Springer Nature remains neutral with regard to jurisdictional claims in published maps and institutional affiliations. 